\title{
Paradigm Uniformity Effects Versus Boundary Effects
}

\author{
Renate Raffelsiefen
}

\section{I INTRODUCTION}

Morphologically complex structures sometimes exhibit sound properties that differ from those occurring in simplexes. The relevant properties concern both distinctive features as in ( $1 a)$ and arguably non-distinctive features as in $(\mathrm{I} b)$. In ( $\mathrm{I} a)$ the occurrence of the diphthong before a stressless syllable closed by a noncoronal obstruent violates the so-called 'Arab Rule' (cf. Fidelholtz 1967; Myers 1987b). ${ }^{1}$ In (Ib) the phonetic contrasts concern several properties: shyness and minus differ both in the length of the diphthong (marked by the superscripts ' +1 ' (+long) versus '-l' (-long) in the narrow transcription in (Ib)) and in the amplitude of $n$. Umeda and Coker (1974: 5) characterize the phonetics of suffix-initial $n$ as 'more consonantal' as opposed to the medial $n$ in words like minus, which is characterized as 'more vocalic'. The relevant contrast is represented by ' $+\mathrm{f}$ ' ('fortition') versus ' $-\mathrm{f}$ ' ('lenition') in ( $\mathrm{I} b$ ). Because of those phonetic

I wish to thank Laura Downing, T. Alan Hall, and an anonymous reviewer for comments on an earlier version. I also thank Caroline Féry, Annie Rialland, Roger Schwarzschild, Dan Silverman, Bruce Straub and the audience at the ZAS Conference on Paradigm Uniformity, where the basic arguments for the distinction defended here were first presented.

' The rule has exceptions, especially among proper nouns (cf. Jacob, Josef). 
contrasts the words in ( $\mathrm{I} b$ ) do not rhyme perfectly (cf. Z. D. Harris I951; D. Jones 1956; Wells i990a, $b$ ).

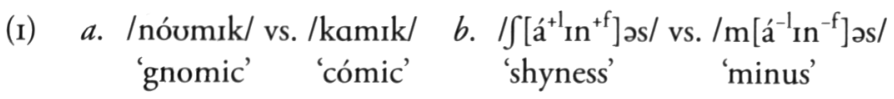

How can the special phonology of the suffixed words in (I) be described? Two traditional explanations invoke a preference for uniform paradigms, that is, a preference for 'sameness' in the sound structure of semantically related units of speech (cf. Humboldt 1836) and 'boundary signals', which function to mark the edges of morphological constituents (cf. Trubetzkoy 1936, 1939: 24I-6I).

To begin with paradigm uniformity (PU), the relevant preference was traditionally conceived to be 'psychological' (i.e. 'one meaning-one form'), inherently conflicting with 'physiological' (i.e. strictly phonologically motivated) preferences, where the conflict concerns surface forms. As is well known, this sort of approach was entirely dismissed in Generative Phonology (for insightful discussion, see Vennemann 1972), but has been revived in Optimality Theory (OT). Specifically, violations of 'regular' phonology due to PU are analyzed in terms of the domination of phonological markedness constraints by PU constraints or output-output correspondence constraints (cf. Benua 1995, 1997a, b; Burzio 1996; Kenstowicz 1996; Kraska-Szlenk 1995; Raffelsiefen I995, 2000). The effect in ( $\mathrm{I} a$ ) could accordingly be described as in (2), where the constraint $\mathrm{Pu}[\mathrm{NuC}]$, which requires identical nuclei for words belonging to a single paradigm, dominates ARAB, the phonological markedness constraint that prohibits heavy nuclei in certain positions. ${ }^{2}$

\begin{tabular}{|c||c|c|}
\hline Base: nóum+Ik & PU[NUC] & ARAB \\
\hline \hline námık & $* !$ & \\
\hline$\checkmark$ nóumık & & $*$ \\
\hline
\end{tabular}

The ranking in (2) explains why the Arab Rule is violated in words like $b[\mathrm{er}]$ sic 'basic' (cf. b[er]se 'base') and an[i:]mic 'anemic' (cf. an [i:] mia 'anemia'), but not in words lacking a relevant base such as traffic, panic, endemic, and polemic.

A perhaps novel proposal is the extension of PU to account for the low-level phonetics illustrated in ( $\mathrm{I} b$ ) (cf. the works discussed in s. 9.5). The idea would be to describe the length of the diphthong in shyness (vis-à-vis the diphthong in minus) also as a PU effect, based on vowel length in the free-standing word shy as in $(3 a)$.

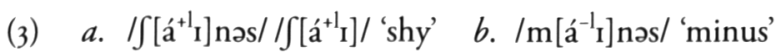

\footnotetext{
${ }^{2}$ I assume with McCarthy (Ch. 8 above) that PU effects are restricted by 'Base Priority' (cf. Benua 1997) unless the concept of a base does not apply, as in inflectional morphology (especially in agreement morphology, cf. Raffelsiefen 1995).
} 
Steriade (2000) emphasizes the theoretical implications of a PU-based description for the phonology-phonetics interface. To be affected by PU constraints, phonetic features must be represented in the lexicon. If universally non-distinctive features could be shown to be affected by PU the distinction between phonology and linguistic phonetics would break down and the notion of distinctiveness would lose its relevance.

While the conclusion in the preceding sentence follows from the premise ${ }^{3}$ the question of whether the premise applies and a certain 'identity effect' indeed qualifies as a PU effect must be carefully examined. On the second approach to morphophonology mentioned above, that is, descriptions in terms of 'boundary signals', there is no need for lexical representation of the low-level phonetic contrasts illustrated in ( $\mathrm{I} b$ ). That is, on Trubetzkoy's view the rhymes of words like shyness and minus are identical at the phonemic level, and the relevant contrasts would be analyzed as boundary signals representing the delimitative, rather than the distinctive, function of phonology. ${ }^{4}$ In OT, this analysis can be formalized in terms of alignment constraints, which require the edges of morphological constituents to align with phonological constituents (cf. McCarthy and Prince 1993a, a generalization of Selkirk's 1986 edge-based theory of the syntax-prosody interface). The relevant constraints are discussed in more detail below. For now it suffices to assume that shyness and minus are lexically represented as in (4a), that words are systematically aligned with phonological word boundaries such that suffixes are excluded as in $(4 b)$, and that feet and syllables must be properly contained within phonological words (henceforth pwords) as in (4c) (' $\omega$ ' = pword, ' $\Sigma$ ' = foot):

(4) a. $\left[\left[\int_{\text {ár }}\right]_{\text {STEM }}[\text { nəs }]_{\text {SUFFIX }}\right]_{\text {WORD }}$
'shyness' $b$.

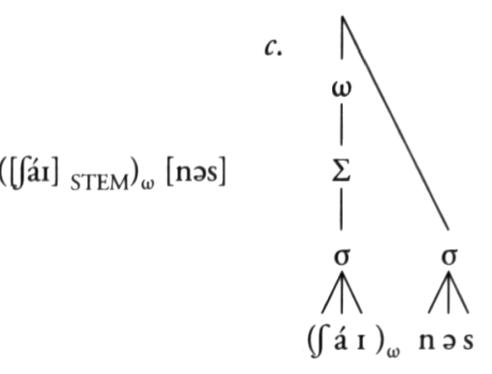

[máinəs $]_{\text {WORD }}$ 'minus'
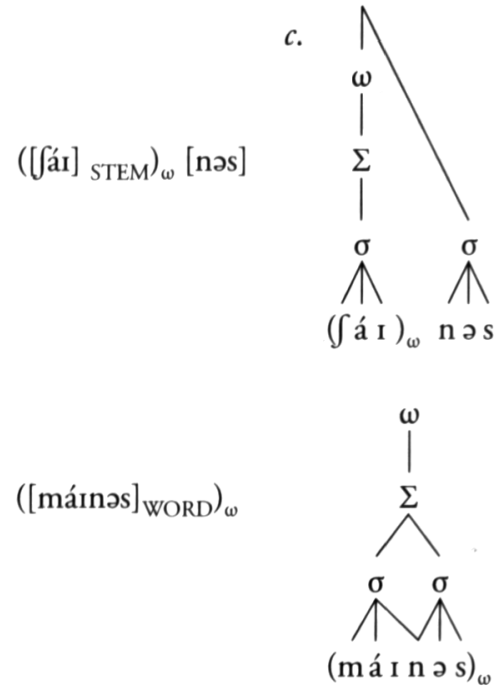

\footnotetext{
3 The conclusion follows from the premise provided that the relevant features are indeed affected by PU constraints directly (cf. Davis (Ch. 5 above), see also n. 61).

${ }^{4}$ Trubetzkoy does not discuss this particular example but comparable cases like we learn versus will earn, where the phonetic differences observed for the $l$ are analyzed as boundary effects derived from identical phonemic representations.
} 
Given the representations in $(4 c)$ the length contrasts of the diphthongs as well as the contrasts in the amplitude of the $n$ in ( $\mathrm{I} b$ ) result from a contrast in prosodic organization. That is, the fact that the diphthong in shyness exhibits the phonetic properties of word-final (or foot-final) diphthongs is conditioned by the fact that this diphthong does indeed occur in pword-final (and foot-final) position, as opposed to the diphthong in minus. Similarly, the fact that the $n$ in shyness exhibits 'initial' phonetics (cf. Umeda and Stoker 1974: 5) results from the syllabification of this $n$ as an exclusively syllable-initial consonant, again as opposed to the $n$ in minus, which also closes the preceding stressed syllable. 5 One important difference between the two descriptions is then that in (4) all phonetic properties of both shyness and minus are canonical in that they are determined by the position of speech sounds within prosodic constituents, whereas on the PU analysis in ( $3 a$ ) the phonetics of shyness involves a genuine violation of canonical phonology. A second difference is that the description in (4) accounts for both the difference in the length of the diphthong and the difference in the amplitude of $n$ as two reflections of a single phenomenon (i.e. the location of a specific boundary) whereas the correlation between these two effects is in principle accidental in terms of PU constraints. Moreover, it is debatable whether the 'special phonology' of the $n$ in the suffix -ness can be described as a PU effect because the suffix does not relate to a free-standing form.

It appears then that while often exhibiting converging results, that is, 'surface' resemblance among related words, PU effects and boundary effects are fundamentally distinct. PU effects presuppose the recognition of paradigmatic relations in the lexicon together with a constraint that prohibits phonological variation (at some specific level of abstractness) among paradigm members. In terms of learnability PU effects raise the questions of how learners know the extension of some paradigm (i.e. how they distinguish members from non-members) and how they identify the member which functions as the 'attractor' and hence determines the direction of leveling (cf. Albright, Ch. 2 above, McCarthy, Ch. 8 above). By contrast, boundary effects, which I will also refer to as 'domain effects', presuppose knowledge of syntagmatic structure. In terms of learnability boundary effects raise the questions of how learners recognize morphosyntactic structure and how they learn rules for aligning specific morphological constituent edges with prosodic boundaries.

The question of whether and how PU effects and boundary effects can be distinguished on empirical grounds is vital not only for a proper understanding of PUrelated issues (e.g. Under what conditions can PU effects arise? Which members of a paradigm can function as attractor?) but also is of crucial significance for the phonology-phonetics distinction. Given the apparent assumption in some recent work that any sort of deviation from simplex phonology observed in morphologically complex words should be analyzed in terms of PU (e.g. Hayes 2000; Steriade 2000) the

\footnotetext{
According to Wells (1990b) the $n$ in minus is simply a coda consonant whereas the $\underline{\mathrm{n}}$ in shyness forms an onset.

6 The citation marks are used here because the precise meaning of 'surface' is the bone of contention here.
} 
main concern of this chapter is to develop criteria for recognizing boundary effects (cf. s. 9.2). The application of the relevant criteria to English in 5.9 .3 is the basis for the discussion of major empirical differences between PU effects and boundary effects in s. 9.4. In s. 9.5 I discuss some descriptions that I consider marred by the failure to properly distinguish PU effects from boundary effects, focusing on poorly motivated use of PU constraints. In s. 9.6 I conclude.

\subsection{GENERAL CRITERIA FOR RECOGNIZING}

\section{BOUNDARY EFFECTS}

A brief review of Dixon's (1977) work on pwords in Yidin in s. 9.2.I will serve as a basis for developing criteria for recognizing boundary phenomena in s. 9.2.2. In s. 9.2.3 it is shown that these criteria are not met in the work of Aronoff and Sridhar (1983), Szpyra (1989) and Hammond (1999), arguably as a result of failing to distinguish boundary effects from PU effects. The question of which phonological diagnostics are relevant for recognizing boundary effects in English is discussed in s. 9.2.4.

\subsection{The pword in Yidin}

It is a commonplace observation that morphologically complex words may violate constraints which are satisfied in simplexes. Dixon (1977) cites the Yidin words in (5):

(5)

wánal\#gimbá:l\#du
'boomerang-without-ERG'
bigú:n\#gímbal
'shield—without-ABs'

Constraint violated: *LAPSE

Adjacent unstressed syllables are prohibited *Clash

Adjacent stressed syllables are prohibited

Dixon argues that stress patterns in (5) are explained by the prosodic structure in (6), in that the relevant constraints are satisfied within each pword.

(6) (wána) $)_{\omega}(\text { gimbá:ldu) })_{\omega}$ (bigú:n) $)_{\omega}\left(\right.$ gímbal $_{\omega}$

Dixon shows that the pwords in (6) account for clusters of correlating prosodic properties besides stress. Moreover, he discovers that for affixes the number of syllables determines prosodic integration into the stem: monosyllabic affixes are 'coherent', that is, they form a single pword together with the stem, whereas disyllabic affixes are 'non-coherent', that is, they form separate pwords. By contrast, postinflectional affixes, which syntactically function as modifiers (e.g. - di 'self', - la 'now', -bud $d^{y} u n$ 'still'), always form separate pwords, regardless of the number of syllables. Those affixes are referred to as 'MOD' for 'modifiers' in table (7), where Dixon's rule is illustrated with some abstract examples. 
(7) a. $[\sigma \sigma \sigma \sigma]_{\mathrm{WORD}} \quad \rightarrow(\sigma \sigma \sigma \sigma)_{\omega}$

b. $\left[[\sigma \sigma \sigma]_{S T E M}[\sigma]_{S U F F I X}\right]_{W O R D} \rightarrow(\sigma \sigma \sigma \sigma)_{\omega}$

c. $\left[[\sigma \sigma]_{\text {STEM }}[\sigma \sigma]_{\text {SUFFIX }}\right]_{\text {WORD }} \rightarrow(\sigma \sigma)_{\omega}(\sigma \sigma)_{\omega}$

d. $\left[[\sigma \sigma]_{\text {STEM }}[\sigma \sigma]_{\text {SUFFIX }}[\sigma]_{\text {SUFFIX }}\right]_{\text {WORD }} \rightarrow(\sigma \sigma)_{\omega}(\sigma \sigma \sigma)_{\omega}$

e. $\left[[\sigma \sigma]_{\text {STEM }}[\sigma \sigma]_{\text {SUFFIX }}[\sigma]_{\text {MOD }}\right]_{\text {WORD }} \rightarrow(\sigma \sigma)_{\omega}(\sigma \sigma)_{\omega}(\sigma)_{\omega}$

The term WORD in (7) refers to the 'grammatical word'. The examples in $(7 a, b)$ illustrate a certain type of neutralization resulting from cohesion, where distinct morphological structures are mapped into identical prosodic domains.

\subsubsection{Restrictions on syntax to prosody mapping}

Based on Dixon's description of Yidin I will propose certain criteria for restricting boundary analyses where the restrictions concern the input, the output, and the mapping.

\subsubsection{Restrictions on the input}

The structure of the input forms must be independently motivated. In (7) this condition is satisfied because both the distinction between affixes and modifiers and the distinction between monosyllabic and disyllabic affixes can be established independent of the aspects of surface prosody to be explained (e.g. foot structure, vowel lengthening).

\subsubsection{Restrictions on the output}

Within the theory of prosodic phonology, prosodic constituents are defined in terms of their relation to other constituents within the prosodic hierarchy. The relevant part of the prosodic hierarchy is given in (8).

(8)

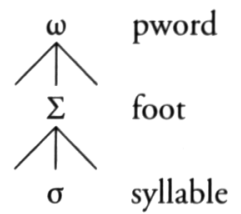

The prosodic hierarchy is subject to the Strict Layer Hypothesis (cf. Selkirk 1981), which consists of two constraints, here referred to as Headedness (cf. Selkirk 1995) and Containment. The definitions given below are adopted from Nespor and Vogel (1986: 7). ${ }^{7}$

\section{(9) a. Headedness}

A given non-terminal unit is composed of one or more units of the immediately lower category.

(e.g. a pword dominates at least one foot)

7 Peperkamp (1997: 37) describes the second clause of the original Strict Layer Hypothesis by a constraint 'Proper Nesting', defined in terms of alignment. 


\section{b. Containment}

A unit of a given level is exhaustively contained in the superordinate unit of which it is a part.

(e.g. feet are properly contained within pwords)

In this study both Headedness and Containment are assumed to be inviolable constraints. ${ }^{8}$ Deviations from simplex phonology caused directly by the satisfaction of either of these constraints are referred to as boundary effects (cf. s. 9.5). For instance, the occurrence of stress on adjacent monosyllabic modifiers in Yidin results from the satisfaction of HEADEDNESs and qualifies therefore as a boundary effect.

\subsubsection{Restrictions on the mapping}

The mapping from syntactic to prosodic structure is stated in terms of alignment constraints, where the left or right boundary of some morphosyntactic category ('GCAT' in (IO)) is required to align with the left or right boundary of some prosodic category ('PCAT' in (IO)). 'E' stands for left or right edge (cf. McCarthy and Prince 1993a).
a. Align (GCat, E; PCat, E)
b. Align (PCat, E; GCat, E)

The generality of the constraint schemata in (IO) conflicts with Nespor and Vogel, who define the pword as 'the lowest constituent of the prosodic hierarchy which is constructed on the basis of mapping rules that make substantial use of nonphonological notions' (1986: 107). I assume here that the pword is the lowest constituent of the prosodic hierarchy which necessarily aligns with some grammatical boundary, which means that the constraint in (II) is also taken to be inviolable..$^{10}$

\section{(II) Align ( $\omega, E$; GCat, E)}

The violability of the 'mirror image' constraint Align (GCat, E; $\omega, \mathrm{E}$ ) is demonstrated by the existence of cohering affixes as in Yidin. Assuming that constraints are violated only to satisfy higher-ranking constraints the question arises which constraints crucially dominate alignment constraints thereby causing cohesion. For Yidin, Dixon's generalization that only monosyllabic suffixes cohere indicates the relevance of the phonological markedness constraint FTBIN, which requires binary feet. Specifically, assuming that both HEADEDNESS and CoNTAINMENT are inviolable (cf. s. 9.2.2.2) the ranking in (12) has the desired effect of integrating monosyllabic, but not disyllabic suffixes, into the pword of the stem.

\footnotetext{
${ }^{8}$ These assumptions are not accepted by all linguists. Szpyra (1989) and Hall (1998) propose descriptions in which Headedness is violated. In Hannahs's (1995) description of French, Containment is violated (cf. s. 9.6.3).

9 The constraint in ( $10 a$ ) says: 'For any GCat in the representation, align its (right or left) edge with the (right or left) edge of some PCat.'

10 Peperkamp (1997: 30) argues on the basis of Italian data that pword boundaries do not necessarily coincide with syntactic boundaries. However, the evidence cited in support of this claim is inconclusive because the relevant effects could be PU effects instead.
} 
(i2) Ftbin $\gg$ Align (Suffix, L, $\omega$, L), Align (Suffix, L, $\omega$, R)

Recall that monosyllabic morphemes are not necessarily integrated into the preceding pword but only if they are suffixes. The regular occurrence of monosyllabic feet in modifiers is described by ranking the constraints Align (Mod, L, $\omega, \mathrm{L}$ ) and ALIGN (Mod, R, $\omega, \mathrm{R}$ ) above FTBIN.

\subsubsection{Summary}

It is proposed here to recognize boundary effects if and only if all of the following criteria are satisfied:

(13) a. Both the morphosyntactic and the phonological structure of the input forms are independently motivated.

$b$. The relation between the morphosyntactic structure and the prosodic structure is describable in terms of alignment constraints, such that 'cohesion' follows from constraint domination.

c. Inviolability of the constraint Align ( $\omega, \mathrm{E}$; GCat,E): pword boundaries necessarily align with morphosyntactic boundaries.

d. Inviolability of the constraints Headedness and Containment.

In s. 9.2.3 I briefly discuss some previous work on English morphophonology in terms of pwords which fail to satisfy most of the criteria in (I3). In s. 9.3 I present an alternative description of prosodic domains in English, where all criteria are satisfied. Since noncohesion yields effects that superficially resemble PU effects criterion ( $13 b$ ) will be especially relevant for the empirical distinction between the two types of effects. The working hypothesis to be motivated in this chapter can then be stated as follows:

(I4) If a morphologically complex word exhibits a sound property absent from comparable simplexes, where this property is necessarily entailed (in the respective language) by a domain description satisfying all criteria in (13), then that property should be analyzed as a boundary effect, not a PU effect.

For instance, because of the prosodic domains described by the constraint ranking for Yidin above, a word with a monosyllabic suffix, but not words containing disyllabic suffixes or modifiers, may exhibit stress 'shift'. Stress 'neutrality' in the latter cases is accordingly a boundary effect, not a PU effect.

\subsubsection{Previous pword-based analyses of English morphophonology}

The core idea of the descriptions of English to be reviewed here is to use pwords to account for so-called stress neutrality. Stress neutrality is often associated with specific affixes and can be illustrated with the examples in ( $15 a$ ) versus (I5b):
a. 'stress-shifting' affixes rádical+ity $\rightarrow$ ràdicálity phónème+ic $\rightarrow$ phonémic

b. 'stress-neutral' affixes rádical+ness $\rightarrow$ rádicalness devélop+ment $\rightarrow$ devélopment 


$$
\begin{array}{ll}
\text { sólid+ifý } \rightarrow \text { solídify } & \text { hóspital+íze } \rightarrow \text { hóspitalìze } \\
\text { Sudán+ése } \rightarrow \text { Sùdanése } & \text { seléct+ée } \rightarrow \text { selèctée }
\end{array}
$$

All words in $(15 b)$ exhibit some type of irregular stress pattern, including three adjacent stressless syllables (e.g. rádicalness), no stress on a closed penultimate syllable (e.g. devélopment), internal sequences of unstressed syllables in verbs (e.g. hóspitalize), and ${ }^{*}$ Clash-violations (e.g. selèctée). No such patterns are seen in comparable simplexes (e.g. the verb eliminàte, not *éliminàte, guàrantée, not *guaràntée). Aronoff and Sridhar (1983) propose to describe stress-neutrality by excluding 'stress-neutral' affixes from the pword of the stem. This proposal, which is adopted by Szpyra (1989) and Hammond (1999), is illustrated in (16).

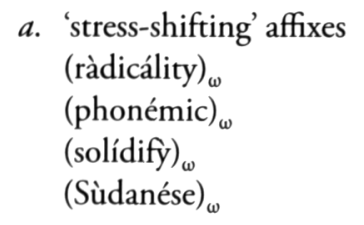

b. 'stress-neutral' affixes
(rádical) $)_{\omega}$ ness
(devélop) $)_{\omega}$ ment
(hóspital) $)_{\omega}$ ize
$(\text { selèct })_{\omega}$ ée

The prosodic structures in (16) account for stress violations and also satisfy criterion $(\mathrm{I} 3 \mathrm{c})$ in that all pword boundaries align with morphosyntactic boundaries. However, the other criteria in ( 13 ) are not satisfied. Criterion ( $13 a)$ is not met because the distinction between the category 'STEM' and 'WORD' as in (17), which determines prosodic integration in Aronoff and Sridhar's description, is not motivated on syntactic grounds but merely encodes the distinct phonological effects of affixation: ${ }^{\text {II }}$

$$
\begin{aligned}
& \text { a. }[\text { radical }]_{\mathrm{STEM}}+\mathrm{ity} \text { b. }[\text { radical }]_{\mathrm{WORD}}+\text { ness } \\
& {[\text { phoneme }]_{\mathrm{STEM}}+\mathrm{ic} \quad[\text { develop }]_{\mathrm{WORD}}+\text { ment }} \\
& {[\text { solid }]_{S_{T E M}}+\text { ify } \quad[\text { hospital }]_{\text {WORD }}+\text { ize }} \\
& {[\text { Sudan }]_{S_{T E M}}+\text { ese } \quad[\text { select }]_{\text {WORD }}+\text { ee }}
\end{aligned}
$$

The same criticism applies to Szpyra (1989), who proposes an algorithm for mapping the 'syntactic' structures in (I8) into prosodic structures. Again, the syntactic representation of the suffix -ity with no left bracket, as opposed to the representation of the suffixes -ness or -ize with a left bracket, serves no other purpose than to account for stress neutrality.
a. $[$ radical $]+$ ity $] \rightarrow{\text { (radicality })_{\omega}}$
b. $[$ [radical $][+$ ness $] \rightarrow(\text { radical })_{\omega}(\text { ness })_{\omega}$
c. $\left[[\right.$ alcohol $][+\mathrm{ize}] \rightarrow(\text { alcohol })_{\omega}(\mathrm{ize})_{\omega}$

Hammond (1999) does not attempt to analyze the difference between stress-neutral and stress-shifting suffixes in quasi-syntactic terms but formulates the constraint

\footnotetext{
II Aronoff and Sridhar's rule for constructing pwords says 'Assign a pword boundary to the edge of any element which is a member of a major lexical category unless that edge is adjacent to a stem affix' (1983: 15). 'Stem affixes' differ from 'word affixes' with respect to 'the category of elements to which they attach' (ibid. 13)).
} 
Neutrality, which says that 'Certain affixes cannot be in the prosodic word' (1999: 327). ${ }^{12}$ The wording 'certain affixes', which reveals the entirely diacritic character of the rule, stands for the suffixes -ist, -ly, -ance, -ence, -ant, -ent, -er, -age, -al, -ive, -ment, -less, $-y$, -able, -ish, -ism, -ed, -en, -s, -ous, -ure, -dom, -ness, -ace, -ian, -ward, -or, -t, -ton, -ate, -ite, -ine, -hood,-ize, -itude, -ful, -eme, -ship, -ette, -ee, -ée, -eer, -ade, -ine, -esque (Hammond 1999: $325-7)$. $^{13}$

Violation of criterion (13a) correlates with the violations of criteria $(13 b, d)$. Specifically, the structure in (19), which is assumed in all descriptions under review, violates the constraint CONTAINMENT, in that syllables are not properly contained within pwords.

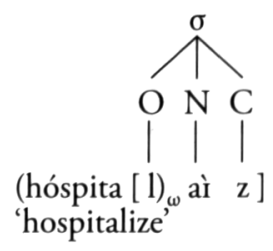

In the descriptions reviewed here CONTAINMENT is violated whenever a consonantfinal stem precedes a stress-neutral, vowel-initial suffix. In addition, some of Szpyra's structures also violate the constraint HeAdedness, in that pwords have no stress (e.g. (ness) $)_{\omega}$ in $(18 b)$ ). Finally, all three analyses fail to obey criterion (13b), in that the question of why cohesion occurs is not addressed, let alone explained.

The joint failure of these descriptions to satisfy criteria $(\mathrm{r} 3 a, b, d)$ results from a single cause, namely the idea that stress-behavior requires a unified treatment. For the related language Dutch, Booij (1977: 85) notes that "The decisive criterion for which a boundary must be associated with an affix is not its stress behavior but its influence on the syllabification patterns of the complex word in which it occurs.' In his subsequent work he identifies the relevant boundaries as pword boundaries (cf. Booij 1983, 1995). In s. 9.3 it is shown that once syllable structure is identified as the main diagnostic for recognizing pwords a description for which all criteria in (13) are satisfied becomes feasible. On that description there are two distinct sources of stress-neutrality (which in many cases overlap and yield identical results): in words with noncohesive suffixes stress-neutrality is analyzable as a boundary effect (i.e. to satisfy ConTAINMENT) whereas in words with cohesive suffixes it can only be a PU effect (cf. s. 9.4). Before reviewing evidence for this proposal the precise aspects of syllable structure serving as diagnostics for pword structure are discussed in s. 9.2.4.

I2 The term 'prosodic word' is a synonym for 'phonological word'.

${ }_{13}$ The omission of -let, -ling, -ing is presumably an oversight. The list also includes a few questionable items (e.g. stress in -ous-suffixation never falls to the left of the antepenultimate syllable as in gelátinous based on gélatine). 


\subsubsection{Syllable-structure related diagnostics for recognizing pword structure}

The specific contexts for fortition versus lenition in English simplexes are well-known indicators of syllabification principles (cf. Kahn 1976). The relevant phonetic contrasts can be observed for all consonants (cf. Umeda and Coker 1974) but are most conspicuous for $t$. In $(20 a, b)$ aspiration, a type of fortition, indicates onset syllabification whereas glottalization in $(2 \mathrm{O} c)$ or flapping in $(2 \mathrm{O} d, e)$ are types of lenition, which indicate coda association. The data in (20) accordingly suggest that a consonant followed by a stressed vowel is syllabified exclusively as an onset. Another consonant may intervene provided that the cluster exhibits a sonority increase and occurs word-initially (e.g. $t r$, but not $t l, s t$ ). Other postvocalic consonants are associated with coda position, where a following vowel may give rise to ambisyllabicity manifested in flapping (cf. Kahn 1976).

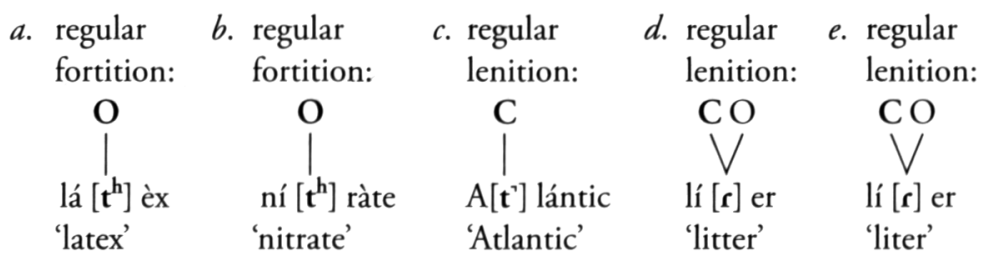

Violations of the patterns in (20) abound. Specifically, lenition in $(2 \mathrm{I} a, b)$ indicates coda association, although exclusive onset syllabification is expected. Similarly, fortition in (2Ic) indicates exclusive onset syllabification, even though (ambisyllabic) coda association would be expected.

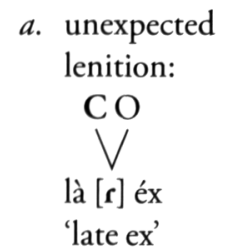
b. unexpected lenition:<smiles>C=IC</smiles><smiles>[GeH2]=[GeH2]</smiles> 'night rate'

c. unexpected fortition:

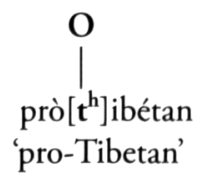

The choice of syllable-structure related properties such as fortition or lenition as decisive diagnostics for recognizing pword structure is supported by the generalization in (22), which is free of exceptions.

(22) Unexpected lenition indicates that a grammatical boundary follows immediately (e.g. là [c]\# éx 'late ex', ní[t']\#ràte 'night rate').

Unexpected fortition indicates that a grammatical boundary precedes immediately (e.g. prò\# $\left[\mathrm{t}^{\mathrm{h}}\right]$ ibétan 'pro-Tibetan').

Apart from satisfying criterion (13c) (i.e. necessary alignment of pword boundaries with grammatical boundaries) the pwords recognized on the basis of 'unexpected' 
lenition or fortition (as opposed to stress-related diagnostics) also invariably satisfy Containment. Satisfaction of Containment can in fact be identified as the very cause of the 'unexpected' syllabification patterns illustrated in (2I). Compare for instance the structures in $(23 a, b)$, where 'expected' onset syllabification of the boldfaced $t$ in night rate would violate CONTAINMENT:

(23)

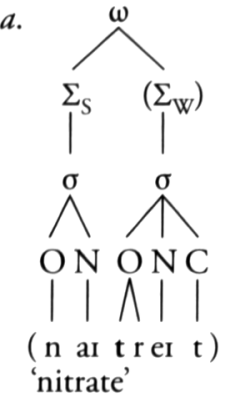

b.

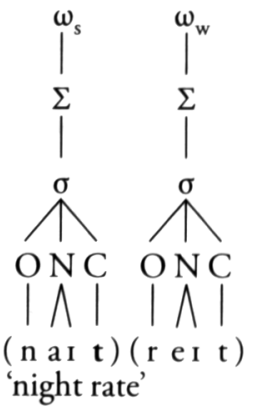

Similarly, the $t$ in pro-Tibetan is prevented from closing the preceding stressed syllable because of undominated ConTAINMENT. The occurrence of lenition in late ex is less clear because flapping possibly indicates ambisyllabicity. Here I follow Kahn who separates the obligatory syllabification of word-final consonants as codas (his rule II) from the 'later' and optional rule of associating such consonants with following vowelinitial words (his rule V). That is, coda association of prevocalic $t$ in $(24 b)$ is necessary to satisfy CONTAINMENT and the relevant structure is preserved in registers where perhaps ONSET is satisfied as well.

(24) $a$.
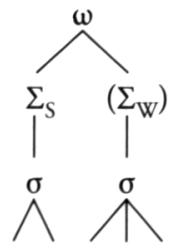

$\mathrm{ONONC}$

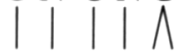

( 1 ei $\mathrm{t}$ e $\mathrm{ks}$ )

'latex' $b$.
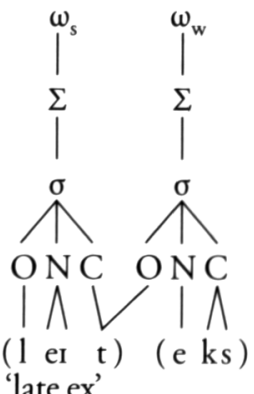

The analysis of the syllabification patterns in $(23 b),(24 b)$ as boundary effects correlates with the satisfaction of HEADEDNESS, manifested by the stability of the weak foot in night rate, as opposed to nitrate (cf. the variant nitr[a]te). Similarly, the stability of the boldfaced pretonic foot in subeditor shown in (25a) correlates with satisfaction of CoNTAINMENT (i.e. 'unexpected' coda syllabification of $b$ before a stressed vowel). Regular phonology of pretonic syllables within single pwords is shown in $(25 b)$, where the (historically related) prefix is prosodically fused with the stem (cf. also [səb] sérvient, 'subservient', [sab] sidiary 'subsidiary'). 
(25)

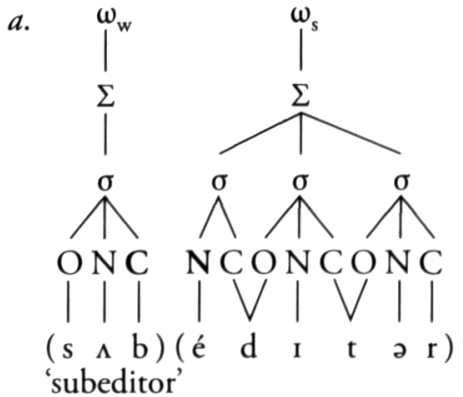

$b$.

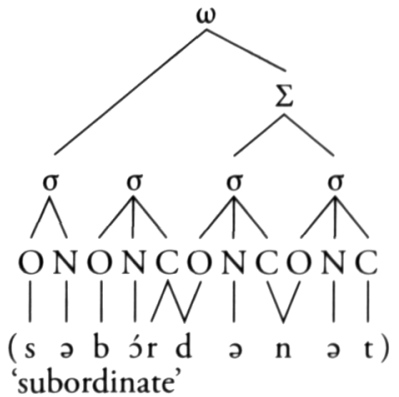

The claim that satisfaction of CONTAINMENT correlates systematically with satisfaction of HEADEDNESs does not entail that every monosyllabic morpheme forms a separate pword and therefore must be stressed. Consider again the example shyness in (26), where fortition of $n$ is a boundary effect which indicates that $n$ does not (ambisyllabically) close the preceding syllable (as opposed to the $n$ in minus). Whether shyness involves recursive pword structure as in $(26 a)$, or not, as in $(26 b)$, both CONTAINMENT and Headedness are satisfied. Note that in (26a) the topmost pword satisfies HEADEDNESs because it dominates a foot (though not immediately).

(26)

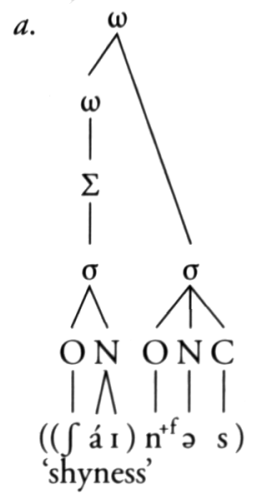

$b$.

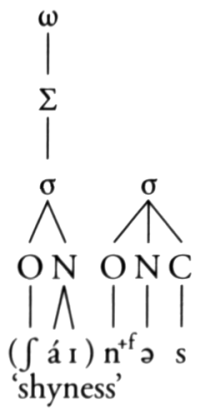

$c$.

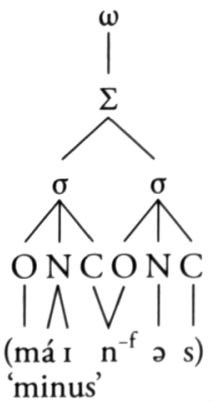

While accounting for 'unexpected' lenition in $(23 b),(24 b)$, the syllabification of the pword-final consonant as a coda raises the question of how to describe the exceptional rhyme structure in those words. The fact that 'superheavy' rhymes such as [art] occur word-finally, but not word-internally (cf. [át.] las, but not *[árt.] las) has led some phonologists to analyze word-final consonants in English as onsets, rather than codas (cf. Giegerich 1985; Kaye, Lowenstamm, and Vergnaud 1990; John Harris 1994; Piggott 1999). ${ }^{14}$ In (27) it is shown that both generalizations could be upheld if one were to distinguish between a phonological (lexical) and a phonetic syllable, such that rhyme

\footnotetext{
${ }^{14}$ According to Piggott (1999), word-final consonants should be analyzed as codas in languages where they have a coda profile and as onsets in languages where they have an onset profile. English clearly represents the latter type.
} 
restrictions are evaluated in the lexicon. The observation that word-final consonants pattern structurally with onsets, but phonetically with codas, is henceforth referred to as 'Final-C effect'.

a. lexical representation:

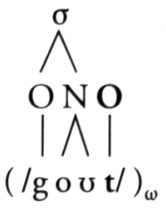

b. phonetic representation:

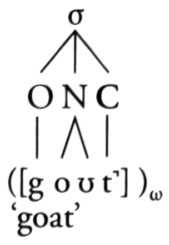

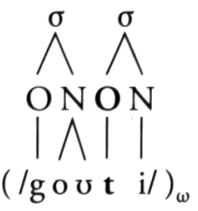

$c$

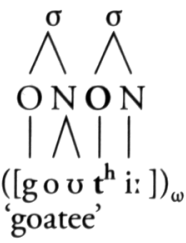

Given the representations in (27), $t$ is 'resyllabified' in goat, but not in suffixed goat$e e$. While the approach to the special status of word-final consonants in $(27 a)$ is by no means cogent ${ }^{15}$ it is adopted here because of the striking parallelism in the distribution of word-final consonants and word-internal onsets (rather than word-internal coda consonants). ${ }^{16}$ Implications of the representation in (27) for possible PU effects are discussed in s. 9.5.2. For now it suffices to state that syllable-based diagnostics for pword structure satisfy criteria (13c) and (13d). Satisfaction of criteria (13a) and (13b) is the topic of $s .9 \cdot 3$.

\subsection{PROSODIC BOUNDARIES IN ENGLISH MORPHOLOGY}

In this section I present morphosyntactic representations of English words, including compounds (cf. s. 9.3.I), prefixed words (cf. s. 9.3.2), suffixed words (cf. s. 9.3.3) and some clitic structures (cf. s. 9.3.4), on the basis of which prosodic boundaries can be described in terms of interacting alignment and markedness constraints. As a result a significant part of English morphophonology is described without invoking PU (or lexical strata). For more details I refer the reader to Raffelsiefen (2004a), a further development and partial revision of my earlier work on the pword in English (cf. Raffelsiefen 1993, 1999a, b). Similar structures are assumed by Hall (2001, 2002).

\footnotetext{
is cf. Hall (2001, 2002) for an alternative analysis, where the special status of pword-final consonants is described by a constraint which requires trimoraic rhymes to align with the right edge of a pword.

${ }^{16}$ Some independent evidence for distinguishing phonological from phonetic principles of syllabification is discussed in Raffelsiefen (2004a).
} 


\subsection{The prosody of compounds}

\subsection{I.I Morphosyntactic structure and alignment}

For compounds I assume the morphosyntactic representations in (28a), which are regularly mapped into the prosodic structures illustrated in (28b). The relevant alignment constraints are stated in $(28 c)$.

$$
\begin{aligned}
& \text { a. } \left.\left[[\operatorname{laIm}]_{\text {Word }}[\text { lait }]_{\text {Word }}\right]_{\text {Word }} \rightarrow b . \quad \text { (laim) }\right)_{\omega}(\text { lait })_{\omega} \\
& \text { c. ALIGN (Word,L; } \omega, \mathrm{L}), \text { ALIGN }(\text { Word,R; } \omega, \mathrm{R})
\end{aligned}
$$

The mapping in (28) is supported by the regular occurrence of boundary effects, including the Headedness effect (i.e. the stability of the final foot in (29a)) and the Final-C-effect (i.e. [aim.l]).
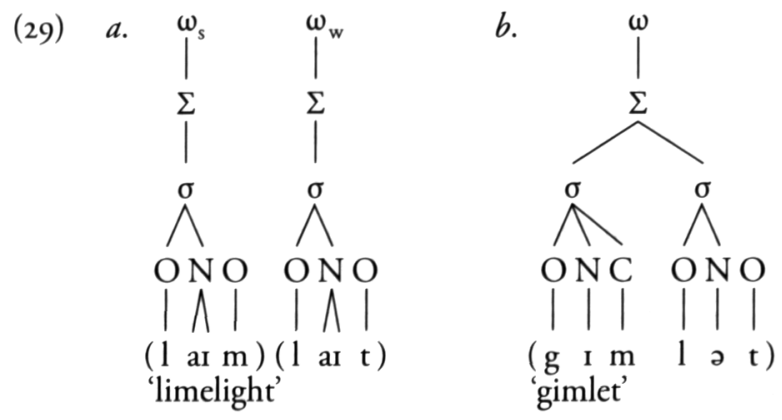

Unmistakable Containment effects are seen in compounds like nigh $\left[\mathrm{t}^{\circ}\right]$ rate 'night rate' or nigh [r]owl 'night owl'.

The rule in (28) accounts for all productive compounding in English and suffices for the purpose of this chapter. Closer scrutiny of the data reveals a systematic asymmetry between compound members. If the righthand member of the compound becomes obsolete thereby losing its word status, fusion results necessarily (e.g. nose- $\nmid$ thyrl(nóstril) ${ }_{\omega}$, know-†leche-(knówledge $)_{\omega}$ ). By contrast, if the lefthand member becomes obsolete boundary effects may persist (e.g. †Tues-day-(Túes) $)_{\omega}(\text { dày })_{\omega}$ ).

\subsubsection{Cohesion}

Compounds do not exhibit systematic phonologically conditioned fusion. There are sporadic cases of historical fusion of formerly separate prosodic constituents as in (30), which I will refer to as 'High Frequency Fusion' (HFF).

(30) (vine) $)_{\omega}(\text { yard })_{\omega}>$ (vinyard) $)_{\omega}$ (sheep $)_{\omega}(\text { herd })_{\omega}>$ (shepherd $)_{\omega}$ (cup) ${ }_{\omega}$ (board) $)_{\omega}>$ (cupboard $)_{\omega}$ (neck) $)_{\omega}(\text { lace })_{\omega}>(\text { necklace })_{\omega}$

HFF differs from other types of fusion discussed below in that it affects the prosodic 
structure of individual words and is insensitive to syntactic structure. ${ }^{17} \mathrm{HFF}$ is instructive in that it reveals the relatedness of 'Final-C' effects, ConTAINMENT effects and

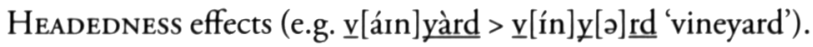

\subsubsection{The prosody of prefixed words}

\subsubsection{Morphosyntactic structure and alignment}

Regarding their prosodic structure, historically prefixed words in English fall into three categories illustrated by the phonetic transcriptions of the verbs seduce, reduce, berate and rerate in (3I) (cf. Raffelsiefen 1999a). ${ }^{18}$ Prosodic structures unattested in simplexes are boldfaced.

$\begin{array}{cll}\begin{array}{c}\text { Phonetic transcriptions } \\ \text { (Wells I990a): }\end{array} & \begin{array}{l}\text { Prosodic } \\ \text { representations: }\end{array} & \\ \text { I [sidjú:s], [sədjú:s] } & (\text { sedúce })_{\omega} & \text { 'seduce' } \\ \text { II [ridjú:s], [rədjú:s], [ri:djú:s] } & \left((\text { re })_{\Sigma}(\text { dúce })_{\Sigma}\right)_{\omega} & \text { 'berate' } \\ \text { [bIréit], [bəréit], [bi:réıt] } & \left((\text { be })_{\Sigma}(\text { ráte })_{\Sigma}\right)_{\omega} & \text { 'reduce' } \\ \text { III [rì:rért] }{ }^{19} & (\text { re })_{\omega}(\text { rate })_{\omega} & \text { 'rerate' }\end{array}$

Phonetically, the (historical) prefix in seduce is indistinguishable from comparable strings in simplexes like sedan, which is transcribed as [sıdǽn], [sədǽn] in Wells (I990a). Since they exhibit no morphophonological effects, category I words are represented as a single pword in (3I).

The claim that prefixes can form separate pwords as in category III is consistent with all diagnostics (cf. Booij and Rubach 1984). The ungrammaticality of reducing the pretonic syllable (cf. ${ }^{*} r$ [ə] ráte) follows from the inviolability of HEADEDNESs. Correlations with CONTAINMENT effects can be observed for consonant-final prefixes (cf. the discussion of subeditor in (25a)). Additional correlations with 'Final- $C$ ' effects are seen in cases like [àvt.r] ún 'outrun', [pòust.g] ráduate 'postgraduate'. Prefixes which form separate pwords differ prosodically from first members of compounds only with respect to relative prominence:
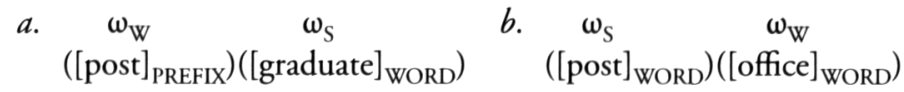

The prosodic motivation for category II in (3I) concerns the fact that for many speakers the prefix in reduce is prosodically distinct from both seduce, which exhibits no effect, and rerate, where the prefix forms a separate pword. Specifically, category II words are typically represented with a third pronunciation in Wells (1990a), which is

${ }^{17}$ HFF may be partially sensitive to phonological properties, specifically the occurrence of perceptually weak boundary signals.

${ }^{18}$ While category I prefixations are typically Romance loanwords and category III prefixations are typically native coinages, category II prefixations include both loanwords (e.g. reduce) and native coinages (e.g. berate)

19 The verb rerate is not listed in Wells but the prefix re- in many comparable words including rerun, rewrite, redo is transcribed with a stress mark and vowel length. 
unattested in simplexes but unlike the prefixes in category III is not transcribed with a separate stress mark (cf. Wells 1990a, Webster's 1984). To account for the relevant prosodic contrasts I tentatively propose the representation in (3I), where the variation characteristic for category II results from the instability of a pretonic foot not forming a separate pword.

I will now present evidence that the three distinct prosodic categories motivated on phonetic grounds in (3I) reflect three distinct syntactic properties of prefixes and are therefore analyzable as boundary effects. Category I includes words for which the (historical) prefix is simply not recognized. The prefixes in category II determine the category of the derived word and function accordingly as heads while those in category III do not affect the category of the derived word and therefore function as modifiers. Assuming that head affixes by definition combine with stems whereas modifier affixes combine with words the prosody of prefixation can be derived from morphosyntactic structures in terms of the alignment constraints in $(28 c)$ and $(33 b) .^{20}$

$$
\begin{aligned}
& \text { a. I [sedúce }]_{\text {WORD }} \rightarrow{\text { (sedúce })_{\omega}} \\
& \text { II }\left[[\text { re }]_{\text {HEAD PREF }}[\text { dúce }]_{\text {STEM }}\right]_{\text {WORD }} \rightarrow\left((\text { re })_{\Sigma} \text { dúce }\right)_{\omega} \\
& {\left[[\text { be }]_{\text {HEAD PREF }}[\text { ráte }]_{\text {STEM }}\right]_{\text {WORD }} \rightarrow\left((\text { be })_{\Sigma} \text { ráte }\right)_{\omega}} \\
& \text { III }\left[[\text { re }]_{\text {MOD PREF }}[\text { ráte }]_{\text {WORD }}\right]_{\text {WORD }} \rightarrow(\text { re })_{\omega}(\text { ráte })_{\omega}
\end{aligned}
$$

According to the description in (33) 'stem recurrence' is irrelevant to the prosody of prefixed words. In fact, se-prefixation never exhibits boundary effects, regardless of stem recurrence as is shown in ( $34 a)$. By contrast, be-, re-, and de-prefixation consistently exhibits boundary effects, even if the stem does not recur as is shown in (34b).

$$
\begin{aligned}
& \text { a. } s[\mathrm{I}] \text { dúce, } s[\partial] \text { dúce, }{ }^{*} s[\mathrm{i}:] \text { dúce 'seduce' reduce, induce, produce, } \\
& \text { deduce, adduce } \\
& s[\mathrm{I}] \text { léct, } s[\partial] \text { léct, }{ }^{*} \mathrm{~s}[\mathrm{i} i] \text { léct } \\
& \text { 'select' elect, prelect, collect } \\
& s[\mathrm{I}] \text { clúde, } s\left[\text { ə] } \text { clúde, }^{*} \mathbf{s}[\mathrm{i} \text { : }]\right. \text { clúde 'seclude' exclude, include, preclude, } \\
& \text { conclude } \\
& \text { b. } \mathrm{b}[\mathrm{r}] \text { gín, b[ว]gín, } \mathbf{b}[\mathrm{i}: \text { gín } \\
& \mathrm{r}[\mathrm{I}] \text { lént, } \mathrm{r}[\mathrm{\partial}] \text { lént, } \mathrm{r}[\mathrm{i}:] \text { lént } \\
& \mathrm{d}[\mathrm{I}] \text { síre, } \mathrm{d}[\text { [ə] síre, } \mathrm{d}[\mathrm{i} \text { : }] \text { síre }
\end{aligned}
$$

$\begin{array}{ll}\text { 'begin' - } & - \\ \text { 'relent' - } \\ \text { 'desire' - }\end{array}$

Why is a prefix recognized in $(34 b)$, but not in $(34 a)$ ? The prefixes in $(34 b)$ relate to a category III-prefix (e.g. re-, de-, pre-) or occur in combination with words. For instance, on the basis of the type of words in $(35 a, b)$ learners infer that $b e$-is a head prefix. This

\footnotetext{
${ }^{20}$ It might be objected that the distinct morphosyntactic representations of seduce versus reduce in (33a) fail to account for the shared 'duce - duct' alternation observed for various verbs ending in -duce (e.g. reduce-reduction, induce-induction, seduce - seduction). However, such alternations can be shown to 'survive' in words which synchronically are clearly analyzed as simplexes such as German fressen 'eat (of an animal)', past tense: fraß (where initial [fr] is the fused reflex of the prefix ver-) which continues to pattern with the historical base essen 'eat (of a person)', past tense: aß.
} 
knowledge is then applied to all verbs or adverbs where the prefix be-can be recognized with the result that the remaining part of the word is categorized as 'STEM':

$$
\begin{array}{rll}
\text { a. } & {\left[[\text { be }][\text { little }]_{\text {ADJ }}\right]_{\text {VERB }}} & \\
& {\left[[\text { be }][\text { witch }]_{\text {NOUN }}\right]_{\text {VERB }}} & \text { If }[\text { beX }]_{\text {VERB }} \text {, then }\left[[\text { be }]_{\text {HEAD PREF }}[\mathrm{X}]_{\text {STEM }}\right]_{\text {WORD }} \\
& {\left[[\text { be }][\text { devil }]_{\text {VERB }}\right]_{\text {VERB }}} \\
\text { b. } & {\left[[\text { be }][\text { low }]_{\mathrm{ADJ}}\right]_{\text {ADVERB }}} & \\
& {\left[[\text { be }][\text { hind }]_{\mathrm{ADJ}}\right]_{\text {ADVERB }}} & \text { If }[\text { beX }]_{\text {ADVERB }}, \text { then } \\
& {\left[[\text { be }][\text { fore }]_{\mathrm{ADJ}}\right]_{\mathrm{ADVERB}}} & {\left[[\mathrm{be}]_{\mathrm{HEAD} \mathrm{PREF}}[\mathrm{X}]_{\mathrm{STEM}}\right]_{\text {WORD }}}
\end{array}
$$

The relevance of the syntactic category of the derived words in (35) is indicated by the fact that no prefix is recognized in the adjective benign or the noun regatta (cf. the ungrammatical pronunciations ${ }^{*} b[\mathrm{i}:]$ nígn, $\left.{ }^{*} r[\mathrm{i}] \mathrm{gátta}\right)$. Similarly, the pronunciation ${ }^{*}[\mathrm{i}:]$ duce is unacceptable because there are no verbs which allow for a prefix se- to be recognized. ${ }^{21}$

Whereas the prosody of category II words depends on the recognition of prefixes (rather than recurrent stems) the prosody of category III words depends on the syntactic relation between the prefixed word and its base. If they commute the prefix is classified as an optional modifier and mapped into a separate pword (the symbol ' $\leftrightarrow$ ' indicates commutation in $(36)):^{22}$

$$
\begin{aligned}
& \text { If }\left[[\mathrm{X}]_{\mathrm{PREF}}[\mathrm{Y}]\right]_{\mathrm{WORD}} \leftrightarrow[\mathrm{Y}]_{\mathrm{WORD}} \text {, then }\left[[\mathrm{X}]_{\mathrm{MODPREF}}[\mathrm{Y}]_{\mathrm{WORD}}\right]_{\mathrm{WORD}} \\
& \text { Example: Mary [rewrote } \leftrightarrow \text { wrote }] \text { the letter. }
\end{aligned}
$$

If the syntactic condition in (36) is satisfied even non-recurring prefixes like ab- reg-

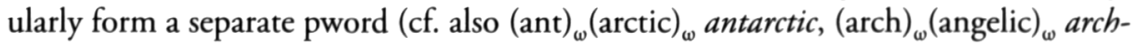
angelic):

$$
\begin{aligned}
& {[\text { abnormal } \leftrightarrow \text { normal }] \text { (behavior) }} \\
& \text { therefore }\left[[\mathrm{ab}]_{\text {MOD PREF }}[\text { normal }]_{\text {WORD }}\right]_{\text {WORD }} \rightarrow(\mathrm{ab})_{\omega}(\text { normal })_{\omega}
\end{aligned}
$$

Similarly, all prefixes in $(38 a)$, but none of the (historical) prefixes in $(38 b)$, function as modifiers and consequently form separate pwords:

$$
\begin{aligned}
& \text { a. } \left.\left[[\mathrm{mis}]_{\mathrm{MOD} \mathrm{PREF}}[\text { allíance }]_{\mathrm{WORD}}\right]_{\mathrm{WORD}} \rightarrow(\text { mis })_{\omega}(\text { allíance })_{\omega} \text { b. (mísanthròpe) }\right)_{\omega} \\
& \text { (mis) }{ }_{\omega} \text { (allíance) }{ }_{\omega} \\
& {\left[[\mathrm{im}]_{\text {MOD PREF }}[\text { móbile }]_{\text {WORD }}\right]_{\text {WORD }} \rightarrow(\text { ìm })_{\omega}\left(\text { móbile) }{ }_{\omega} \quad \text { (immédiate) }\right)_{\omega}} \\
& \left.\left.\left.\left[[\text { in }]_{\text {MOD PREF }}[\text { élegant }]_{\text {WORD }}\right]_{\text {WORD }} \rightarrow \text { (ìn }\right)_{\omega} \text { (élegant) }\right)_{\omega} \quad \text { (insípid) }\right)_{\omega} \\
& \left.\left[[\mathrm{il}]_{\text {MOD PREF }}[\text { légal }]_{\text {WORD }}\right]_{\text {WORD }} \rightarrow(\text { (il })_{\omega}(\text { légal })_{\omega} \quad \text { (illúsive) }\right)_{\omega}
\end{aligned}
$$

For phonetic evidence that even assimilating prefixes can form separate pwords I refer the reader to Wells (1990a) (cf. Webster's 1984), where prefixes functioning as modifiers are distinct with respect to syllabification and stress from (etymologically) related

${ }^{21}$ This description differs from previous 'stem-oriented' approaches, where reduce and seduce are represented on a par (e.g. re=duce, se=duce in Chomsky and Halle (1968)).

${ }^{22}$ Occasional apparent counter-examples such as the intransitive use of reconsider, where the prefix forms a separate pword, ( $\sqrt{ }$ Mary reconsidered versus * Mary considered $)$ are best understood as elliptical. 
prefixes which do not function as modifiers (for detailed discussion, cf. Raffelsiefen 1993, 1999a). The phonetic facts accordingly argue against descriptions where putative 'level-I-properties' such as assimilation are used as evidence to motivate integration of the prefix iN-into the pword of the stem (cf. Szpyra 1989).

The syntactic determination of prosodic form observed in prefixation is part of the larger generalization that modifier function words as in (39a) form separate pwords whereas head function words illustrated in $(39 b)$ do not. Again, the syntactic classification is based on optionality as in (39a) versus obligatoriness as in (39b):

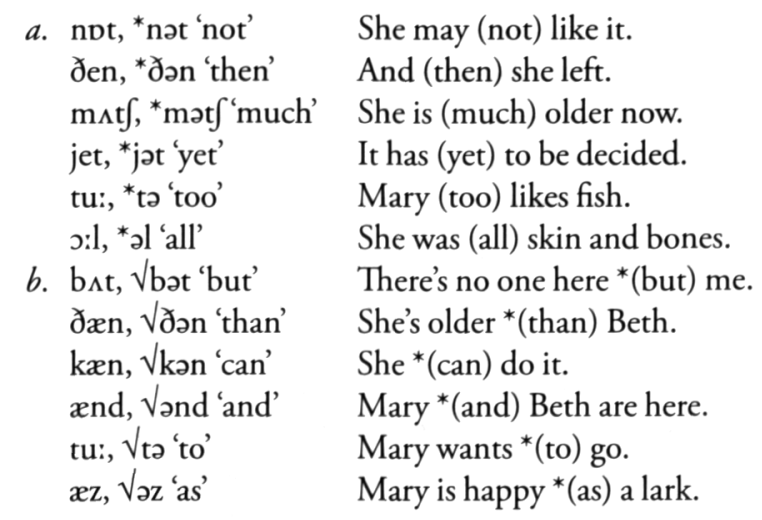

The seemingly mysterious absence of the weak form * ${ }^{*}$, , perhaps first noted by Zwicky (1977), is characteristic for modifiers. Given the mapping in (40a) this absence follows from the necessary satisfaction of HEADEDNESs and is hence a boundary effect. The generalization that function words do not form separate pwords (cf. Selkirk 1995) should accordingly be restricted to head function words for English:

(40) a. [not $]_{\text {MOD FW }} \rightarrow$ (not) ${ }_{\omega}$

b. $[\text { but }]_{\mathrm{HEADFW}} \rightarrow$ (but $)_{\Sigma}$

Given that affixes are also function words the prosody of prefixation follows the pattern illustrated in (40). Note that the generalizations in question cannot be mimicked in terms of PU constraints.

\subsubsection{Cohesion}

Category I prefixes cohere by definition whereas category III prefixes exhibit only HFF illustrated in (4Ia) (compared to regular prosody in $(4 \mathrm{I} b))$ :

$$
\begin{aligned}
\text { a. } & (\text { disintegrate })_{\omega} \\
& (\text { mistake })_{\omega} \\
& (\text { extraordinary })_{\omega}
\end{aligned}
$$$$
\text { b. (dis) })_{\omega}(\text { organize })_{\omega}
$$

$$
\begin{aligned}
& \text { (mis) } \left.)_{\omega} \text { (print }\right)_{\omega} \\
& \left.(\text { extra })_{\omega} \text { (marital }\right)_{\omega}
\end{aligned}
$$

Fusion in (4Ia) is not a synchronic process but is a fact about individual words, comparable to the fused compounds in (30). Contracted n't forms mentioned above also exhibit this sort of fusion (e.g. (won't) ${ }_{\omega}$, (can't) $)_{\omega}$ versus may $\left.(\text { not })_{\omega}\right)$. 
Unlike modifier prefixes, head prefixes exhibit regular phonologically conditioned cohesion. In (42a) a monosyllabic prefix is followed by a stem with an initial stressless syllable. $\mathrm{A} \mathrm{C}_{\mathrm{i}}$-final prefix is followed by a vowel-initial stem in $(42 b)$ and by a $\mathrm{C}_{\mathrm{j}}$-initial stem in $(42 c)$, where $C_{i}$ and $C_{j}$ are consonants which may differ only in voicing.

$$
\begin{aligned}
& \text { a. }\left[[\mathrm{re}]_{\text {HEAD PREF }}[\text { concíle }]_{\text {STEM }}\right]_{\text {WORD }} \rightarrow{\text { (réconcile })_{\omega}} \\
& {\left[[\mathrm{im}]_{\text {HEAD PREF }}[\text { becíle }]_{\text {STEM }}\right]_{\text {WORD }} \rightarrow{\text { (ímbecile })_{\omega}}} \\
& {\left[[\text { de }]_{\text {HEAD PREF }}[\text { rogáte }]_{\text {STEM }}\right]_{\text {WORD }} \rightarrow \text { (dérogàte) }{ }_{\omega}} \\
& \text { b. }\left[[\text { dis }]_{\text {HEAD PREF }}[\text { áster }]_{\text {STEM }}\right]_{\text {WORD }} \rightarrow{\text { (disáster })_{\omega}} \\
& \left.\left[[\mathrm{en}]_{\text {HEAD PREF }}[\text { ámor }]_{\text {STEM }}\right]_{\text {WORD }} \rightarrow \text { (enámor) }\right)_{\omega} \\
& \left.\left[[\text { sub }]_{\text {HEAD PREF }}[\text { órdinate }]_{\text {STEM }}\right]_{\text {WORD }} \rightarrow \text { (subórdinate }\right)_{\omega} \\
& \text { c. } \left.\left[[\text { sub }]_{\text {HEAD PREF }}[\text { poéna }]_{\text {STEM }}\right]_{\text {WORD }} \rightarrow \text { (su[p]oéna) }\right)_{\omega} \text { 'subpoena' } \\
& {\left[[\mathrm{en}]_{\text {HEAD PREF }}[\text { nóble }]_{\text {STEM }}\right]_{\text {WORD }} \rightarrow \text { (e[n]óble) }{ }_{\omega} \text { 'ennoble' }} \\
& \left.\left[[\mathrm{im}]_{\text {HEAD PREF }}[\text { mérse }]_{\text {STEM }}\right]_{\text {WORD }} \rightarrow \text { (i[m]érse) }\right)_{\omega} \text { 'immerse' }
\end{aligned}
$$

Cohesion in (42a) can be described in terms of domination of alignment constraints by phonological markedness constraints. The observation that a head prefix followed by a stem with an initial stressless syllable never exhibits boundary effects is described by ranking Ftbin above Align (Head Prefix, E; $\Sigma$, E) (cf. the similar effects in Yidin). This is because the initial stressless stem syllable is integrated into the syllable headed by the prefix to satisfy FTBIN. This specific effect is ruled out for stems with initial stress with the result that the regular boundary effects in the verbs in (43a) are absent in the respective cognate nouns in $(43 b)$, where the prefixes regularly cohere. The fused words in $(43 b)$ are prosodically indistinguishable from simplexes (cf. restrictions on vowel quantity as in $d[\mathrm{è}]$ rivátion, [é]lefant, not ${ }^{*} d[\mathrm{i}:]$ rivátion, ${ }^{*}[\mathrm{i}:]$ lefant). ${ }^{23}$

$$
\begin{aligned}
& \text { a. }\left[[\mathrm{de}]_{\mathrm{HEAD} \mathrm{PREF}}[\text { ríve }]_{\mathrm{STEM}}\right]_{\mathrm{WORD}} \rightarrow\left((\mathrm{d}[\mathrm{i}:])_{\Sigma} \text { ríve }\right)_{\omega} \text { 'derive' } \\
& {\left[[\mathrm{re}]_{\text {HEAD PREF }}[\text { fúte }]_{\text {STEM }}\right]_{\text {WORD }} \rightarrow\left((\mathrm{r}[\mathrm{i}:])_{\Sigma} \text { fúte }\right)_{\omega} \text { 'refute' }} \\
& \text { b. }\left[[\mathrm{de}]_{\mathrm{HEADPREF}}[\text { rivátion }]_{\mathrm{STEM}}\right]_{\mathrm{WORD}}{ }^{24} \rightarrow(\mathrm{d}[\mathrm{e}] \text { rivátion })_{\omega} \text { 'derivation' } \\
& \left.\left[[\text { re }]_{\text {HEAD PREF }}[\text { futátion }]_{\text {STEM }}\right]_{\text {WORD }} \rightarrow \text { (r[è]futátion) }\right)_{\omega} \text { 'refutation' }
\end{aligned}
$$

The relevant constraint causing cohesion in $(42 b)$ is the constraint ONSET, which requires every syllable to have an onset. In $(42 c)$ it is the constraint ${ }^{*} \mathrm{C}_{\mathrm{i}} \mathrm{C}_{\mathrm{i}}$, which prohibits adjacent consonants with (near) identical features. The ranking is given in (44):

(44) Ftbin, Onset, ${ }^{*} \mathrm{C}_{\mathrm{i}} \mathrm{C}_{\mathrm{i}} \gg$ Align (Head Prefix, E; $\left.\Sigma, \mathrm{E}\right)$

The morphosyntactic structures in (42) are not necessarily meant to represent speaker knowledge. Indeed, the absence of boundary signals in the fused pwords in (42) is likely to prompt (re)analysis of these words as simplexes. The point is that for head prefixes the sort of phonological conditions illustrated in $(42 a, b, c)$ necessarily leads

${ }^{23}$ The dependency of boundary effects on initial stem stress is also seen in (i), where the initial stem syllable can be stressed as a result of being closed.

(i) $\left[[\mathrm{re}]_{\text {HEAD PREFIX }}[\text { láx }]_{\text {STEM }}\right]_{\text {WORD }} \rightarrow\left((\mathrm{r}[\mathrm{i}:])_{\Sigma} \text { láx }\right)_{\omega} \quad$ 'relax' $\left[[\text { re }]_{\text {HEAD PREFIX }}[\text { làxátion }]_{\text {STEM }}\right]_{\text {WORD }} \rightarrow\left((\mathrm{r}[\mathrm{i}:])_{\Sigma} \text { làxátion }\right)_{\omega} \quad$ 'relaxation'

24 The suffix -ation coheres and can therefore be ignored here (cf. s. 9.3.3.2). 
to prosodic fusion. There is thus a real, syntactically conditioned difference between the words in the 'A-rows' in (45), which contain modifier prefixes and yield systematic boundary effects, and the corresponding words in the 'B-rows', which contain head prefixes and do not exhibit boundary effects. ${ }^{25}$
A $\left[[\mathrm{re}]_{\text {MOD PREF }}[\text { combíne }]_{\text {WORD }}\right]_{\text {WORD }}$
$(\mathrm{r}[\mathrm{i}:])_{\omega}(\text { combíne })_{\omega}$ 'recombine'
B $\left[[\mathrm{re}]_{\text {HEAD PREF }}[\text { concíle }]_{\text {STEM }}\right]_{\text {WORD }}$
$\rightarrow \quad(\mathrm{r}[\mathrm{e}] \text { concile })_{\omega}$
'reconcile'
A [[un $\left.]_{\text {MOD PREF }}[\text { áble }]_{\text {WORD }}\right]_{\text {WORD }}$
$\rightarrow(\text { ùn })_{\omega}(\text { áble })_{\omega}$
'unable'
B [[en $\left.]_{\text {HEAD PREF }}[a ́ b l e]_{S T E M}\right]_{\text {WORD }}$
$\rightarrow \quad(\text { enáble })_{\omega}$
'enable'
A $\left[[\mathrm{im}]_{\text {MOD PREF }}[\text { mórtal }]_{\text {WORD }}\right]_{\text {WORD }} \rightarrow(\mathrm{i}[\mathrm{m}])_{\omega}([\mathrm{m}]$ órtal $)$
B $\left[[\mathrm{im}]_{\text {HEAD PREF }}[\text { míngle }]_{\text {STEM }}\right]_{\text {WORD }} \rightarrow(\mathrm{i}[\mathrm{m}] \text { íngle })_{\omega}$
'immortal'
'immingle'

The absence of phonologically conditioned cohesion for modifier prefixes follows from the ranking of the constraint ALIGN (Word,L; $\omega, \mathrm{L}$ ) above the phonological markedness constraints in (44), which also accounts for the absence of the relevant cohesion effects in compounds.

\subsubsection{Suffixation}

\subsubsection{Morphosyntactic structure and alignment}

Unlike prefixes, suffixes never function as modifiers but always as heads. ${ }^{26}$ Analogous to the representation of head prefixes, suffixed words are consequently uniquely represented as $\left[[\mathrm{X}]_{\text {STEM }}[\mathrm{Y}]_{\text {HEAD SUFFIX }}\right]_{\text {WORD. }}$. The morphosyntactic and corresponding prosodic structures are illustrated in (46).

$$
\begin{aligned}
& {\left[[\text { hope }]_{\text {STEM }}[\text { less }]_{\text {HEAD SUFFIX }}\right]_{\text {WORD }} \rightarrow \text { (houp) }{ }_{\omega} \text { las }} \\
& {\left[[\text { whole }]_{\text {STEM }}[\text { some }]_{\text {HEAD SUFFIX }}\right]_{\text {WORD }} \rightarrow(\text { houl })_{\omega} \text { səm }} \\
& {\left[[\text { cool }]_{\text {STEM }}[\text { ness }]_{\text {HEAD SUFFIX }}\right]_{\text {WORD }} \rightarrow(\mathrm{ku}: \mathrm{l})_{\omega} \text { nəs }} \\
& {\left[[\text { taste }]_{\text {STEM }}[\text { ful }]_{\text {HEAD SUFFIX }}\right]_{\text {WORD }} \rightarrow \text { (teIst) }{ }_{\omega} \text { fəl }} \\
& {\left[[\text { duke }]_{\text {STEM }}[\text { dom }]_{\text {HEAD SUFFIX }}\right]_{\text {WORD }} \rightarrow(\text { du: } \mathrm{k})_{\omega} \text { dəm }} \\
& {\left[[\text { ail }]_{\text {STEM }}[\text { ment }]_{\text {HEAD SUFFIX }}\right]_{\text {WORD }} \rightarrow(\text { eil })_{\omega} \text { mənt }}
\end{aligned}
$$

${ }^{25}$ In Webster's (1984), but not in Wells (1990a), immortal and other words including the modifier $i N$ (e.g. illegal, irregular, immoral) are represented with an optional geminate sonorant, as opposed to immingle and other words including a head prefix, which never include a geminate. Wells represents a contrast in syllabification between words like inapt (i.e. insapt), where $i N$ - functions as modifier, and words where it does not function as a modifier (e.g. i\$nert 'inert'). Both dictionaries represent a contrast in stress between modifier prefixes, including $i N$-, which have secondary stress, as opposed to head prefixes. The contrast in syllabification between enable and unable is represented in MacCarthy (1945), but neither in Webster's nor Wells. MacCarthy also distinguishes modifying $i N$-, always transcribed with secondary stress and with [n] before velars (e.g. i[n]cápable, i[n] cómpetent) from head prefixes, which he never marks for secondary stress and transcribes with [n] before velar stops (e.g. $i[\mathrm{n}]$ clóse 'inclose', $i[\mathrm{n}]$ cúr 'incur').

${ }^{26}$ This claim may seem to be contradicted by the fact that the derived form commutes with the base in cases like piglet-pig, waitress-waiter. However, in related languages where grammatical gender distinctions are retained it is seen that the gender of the suffix, rather than the base, invariably determines the gender of the derived word (e.g. German diminutive -chen is neuter, therefore der Stubl ${ }_{\text {MASC }}$ but das Stühlchen ${ }_{\mathrm{NEUT}}$ ). 
The right pword boundary in (46) could be described by positing the constraint ALIGN (Stem, R; $\omega, \mathrm{R}$ ) or, alternatively, the constraint Align, (Head Suffix, L; $\omega, \mathrm{R}$ ). The mapping in (46) is supported by all relevant diagnostics. Apparent violations of rhyme structure are explained if the stem-final consonant is pword-final and consequently associated with an onset in the lexicon. Correlating 'Final-C' and Containment effects are seen in $(47 a)$, where the stem-final consonant has exclusive coda properties (i.e. glottalization), thereby contrasting in a subtle manner with corresponding wordinternal stops as in $(47 b)$. Related effects were observed in shyness versus minus.
a. hó[p'l] ess 'hopeless' lú[k'l]ess 'luckless'
b. dú[pl]icate 'duplicate' dè $[\mathrm{kl}]$ arátion 'declaration'

The analysis of the special phonology reviewed here as boundary effects raises the question of how learners arrive at the underlying morphosyntactic structures in (46). Analogous to the procedure specified for head prefixation I assume that given the occurrence of some suffixations based on free stems as in (48a) learners abstract the affix-based syntactic parsing rule specified in $(48 b)$.

$$
\text { a. } \begin{aligned}
& {\left.[\text { [goal }]_{\text {NOUN }}[\text { less }]\right]_{\mathrm{ADJ}} } \\
& {\left[[\text { time }]_{\text {NOUN }}[\text { less }]\right]_{\mathrm{ADJ}} } \\
& {\left[[\text { tooth }]_{\text {NOUN }}[\text { less }]\right]_{\mathrm{ADJ}} }
\end{aligned}
$$

b.

$$
\begin{aligned}
& \text { If }[[\mathrm{X}][\text { less }]]_{\mathrm{ADJ}}, \\
& \text { then }\left[[\mathrm{X}]_{\text {STEM }}[\text { less }]_{\text {HEAD SUFFIX }}\right]_{\text {WORD }}
\end{aligned}
$$

The result of applying the parsing rule in $(48 b)$ is illustrated in (49). Significantly, syntactic properties of the stem in isolation (i.e. free versus bound) are not represented. ${ }^{27}$

$$
\begin{aligned}
& {\left[[\text { fruit }]_{\text {STEM }}[\text { less }]_{\text {HEAD SUFFIX }}\right]_{\text {WORD }}} \\
& \left.[\text { [gorm }]_{\text {STEM }}[\text { less }]_{\text {HEAD SUFFIX }}\right]_{\text {WORD }} \\
& {\left[[\text { ruth }]_{\text {STEM }}[\text { less }]_{\text {HEAD SUFFIX }}\right]_{\text {WORD }}}
\end{aligned}
$$

To rule out the application of the rule in $(48 b)$ to adjectives such as meticu[los] 'meticulous' frivo[los] 'frivolous' additional criteria have to be invoked, including the presence of a privative meaning and, for literate learners, perhaps also a certain spelling. Importantly, the data from head suffixation confirm the generalization established earlier: if there exist words on the basis of which a head affix can be learned, the words containing that affix exhibit stable boundary effects, whether or not the stem recurs. ${ }^{28}$ Here a significant contrast with PU effects emerges, to be discussed in s. 9.4.3.

\footnotetext{
${ }^{27}$ I disagree here with Hall, who posits 'underlying' pword structure for affixations based on bound stems such as ruthless, as opposed to derived pword structure in affixations based on free stems such as sunless. Hall's claim that in cases like ruthless 'the morphological boundaries were lost but the prosodic structure was retained' (Hall 20oI: 432) conflicts with the fact that native speakers do recognize a suffix in this word and raises the question of why putative loss of morphological structure invariably entails retention of prosodic structure as long as an affix can be recognized, but not otherwise (cf. the cases nostril, seduce s. 9.3.2.I, and pumpkin, s. 9.4.3).

${ }^{28}$ This claim contradicts the common assertion that the category of the stem is crucial to the prosodic organization of suffixed words: 'To describe the types of junction characteristic of a suffix, it is necessary to distinguish two types of theme, independent and dependent. The theme is independent when it may stand alone, without the suffix, as a complete word ... The dependent theme is one which cannot stand alone' (Newman 1948). The opinion expressed in this quote is based on a misinterpretation of the fact that
} 


\subsubsection{Cohesion}

Pwords included in suffixed words are unexceptional in that they are sporadically affected by historical HFF, with concomitant loss of boundary effects. Examples are given in (50).

$$
\begin{aligned}
& \text { (wise) }{ }_{\omega} \text { dom > (wız.dəm) }{ }_{\omega} \text { 'wisdom' } \\
& \text { (worth) } \left.{ }_{\omega} \text { ship > (wer. } \int \partial \mathrm{p}\right)_{\omega} \text { 'worship' } \\
& \text { (hand) }{ }_{\omega} \text { som > (hæn.səm) }{ }_{\omega} \text { 'handsome' } \\
& \text { (friend) } \left.{ }_{\omega} \text { ship > (fren. } \int \partial p\right)_{\omega} \text { 'friendship' }
\end{aligned}
$$

As for systematic phonologically conditioned cohesion, suffixation exhibits interesting parallels to other head affixation discussed in s. 9.3.2.2. Clear evidence for the domination of ALIGN (Stem, R; $\omega, \mathrm{R}$ ) by ONSET is seen in ( $5 \mathrm{I})$, where aspiration of the stem-final consonant indicates the integration of the vowel-initial suffix.

$$
\begin{aligned}
& {\left[[\text { sánit }]_{\text {STEM }}[\text { íze }]_{\text {HEAD SUFFIX }}\right]_{\text {WORD }} \rightarrow\left(\text { sáni }\left[\mathrm{t}^{\mathrm{h}}\right] \text { ìze }\right)_{\omega}} \\
& {\left[[\text { púppet }]_{\text {STEM }}[\text { éer }]_{\text {HEAD SUFFIX }}\right]_{\text {WORD }} \rightarrow\left(\text { pùppe }\left[\mathrm{t}^{\mathrm{h}}\right] \text { éer }\right)_{\omega}} \\
& {\left[[\text { límit }]_{\text {STEM }}[\text { átion }]_{\text {HEAD SUFFIX }}\right]_{\text {WORD }} \rightarrow\left(\text { limimi }\left[\mathrm{t}^{\mathrm{h}}\right] \text { átion }\right)_{\omega}} \\
& \left.[\text { góat }]_{\text {STEM }}[\text { ée }]_{\text {HEAD SUFFIX }}\right]_{\text {WORD }} \rightarrow\left(\text { gòa }\left[\mathrm{t}^{\mathrm{h}}\right] \text { ée }\right)_{\omega}
\end{aligned}
$$

Recall that pword-final consonants are never aspirated, even if a stressed vowel follows. The overall prosodic contrast resulting from distinctions in morphosyntactic structures is illustrated in ( 52$)$, where $\underline{t}$ is associated with coda position in ( $52 a)$, but not in $(52 b){ }^{29}$

$$
\begin{aligned}
& \text { a. } \left.\left[[\text { párrot }]_{\text {WORD }}[\text { éyes }]_{\text {WORD }}\right]_{\text {WORD }} \rightarrow \text { (párro[r] }\right)_{\omega}(\text { èyes })_{\omega} \text { 'parrot eyes' } \\
& \text { b. }\left[[\text { párrot }]_{\text {STEM }}[\text { íze }]_{\text {HEAD SUFFIX }}\right]_{\text {WORD }} \rightarrow\left(\text { párro }\left[t^{\mathrm{h}}\right] \text { ìze }\right)_{\omega} \quad \text { 'parrotize' }
\end{aligned}
$$

Recall that in head prefixation, cohesion also occurs to satisfy the constraint ${ }^{*} \mathrm{C}_{\mathrm{i}} \mathrm{C}_{\mathrm{i}}$. A similar effect is seen in suffixation.

(53) $\left[[\mathrm{X}]_{\text {STEM }}[\text { ty }]_{\text {HEAD SUFFIX }}\right]_{\text {WORD }}$

$\left[[\mathrm{X}]_{\text {STEM }}[\mathrm{ly}]_{\text {HEAD SUFFIX }}\right]_{\text {WORD }}$

$\left[[\mathrm{X}]_{\text {STEM }}[\text { let }]_{\text {HEAD SUFFIX }}\right]_{\text {WORD }}$
a. (frail) ${ }_{\omega}$ ty 'frailty' b. $(\operatorname{modes}[\mathrm{t}] \mathrm{y})_{\omega}$ (night) $)_{\omega}$ ly 'nightly' (woo[l]y) $)_{\omega}$ 'woolly' $\left(\mathrm{pl}\left[\mathrm{e}^{+\mathrm{r}} \mathrm{r}\right]\right)_{\omega}\left[\mathrm{l}^{+\mathrm{f}}\right]$ et $\quad(\text { ow }[\mathrm{l}] \mathrm{et})_{\omega}$ 'owlet' 'playlet'

It should be noted that 'degemination' in $(53 b)$ is a systematic property of the suffixed words since the pronunciations modes[t.t $] y$, ow $[1.1]$ et, woo[1.l] $y$ are clearly ungrammat-

noncohesive affixation overwhelmingly occurs with free stems. For detailed discussion of this point, see Raffelsiefen (2004a, Chapter 7).

${ }^{29}$ The integration of vowel-initial suffixes into the pword of the stem is also observed in German and Dutch. It is sometimes claimed that Dutch -achtig, German -artig are exceptions to this generalization in that they are not integrated into the pword of the stem (Booij 1983; van der Hulst 1984; Peperkamp 1997). At least German -artig is not exceptional in that it is not a suffix, but rather a (probably even complex $\left.[\text { árt }]_{\text {STEM }}[\mathrm{ig}]_{\text {HEAD SUFFIX }}\right]_{\text {WORD }}$ ) word. The distinct prosodic effect of English -átion in (5I) versus German -ártig results accordingly from the distinct morphosyntactic structure (i.e. [[gút $\left.]_{\text {WORD }}[\text { ártig] }]_{\text {WORD }}\right]_{\text {WORD }}$ $\rightarrow$ (gút) $_{\omega}(\text { àrtig) })_{\omega}$. 
ical. Yet, the examples in (54), which include geminates, show that cohesion in $(53 b)$ cannot be described by simply ranking ${ }^{*} \mathrm{C}_{\mathrm{i}} \mathrm{C}_{\mathrm{i}}$ above the relevant alignment constraint.

(54) [[goal $\left.]_{\text {STEM }}[\text { less }]_{\text {HEAD SUFFIX }}\right]_{\text {WORD }}$ $\left[[\text { keen }]_{\text {STEM }}[\text { ness }]_{\text {HEAD SUFFIX }}\right]_{\text {WORD }}$ $\left[[\text { frail }]_{\text {STEM }}[\text { ly }]_{\text {HEAD SUFFIX }}\right]_{\text {WORD }}$ $\left[[\text { embalm }]_{\text {STEM }}[\text { ment }]_{\text {HEAD SUFFIX }}\right]_{\text {WORD }}$ $(\text { goa[l] })_{\omega}[1]$ ess 'goalless' $(\mathrm{kee}[\mathrm{n}])_{\omega}[\mathrm{n}]$ ess 'keenness' $(\text { frai }[1])_{\omega}[1] y$ 'frailly' $(\mathrm{embal}[\mathrm{m}])_{\omega}[\mathrm{m}]$ ent 'embalmment'

One of the main claims defended here is that cohesion, unlike PU behavior, is not an idiosyncratic property of individual affixes. There is indeed an independent property which distinguishes the suffixes in (53) and (54). For each suffix in (53) a corresponding suffix exists, which has identical morphosyntactic properties and differs only in the absence of the initial consonant.

$$
\begin{aligned}
& \text { a. }-[\mathrm{ti}]_{\mathrm{N}}{ }^{-}-[\mathrm{i}]_{\mathrm{N}} \\
& -[\mathrm{li}]_{\mathrm{A}}{ }^{-}-[\mathrm{i}]_{\mathrm{A}} \\
& -[\mathrm{l} t]_{\mathrm{N}}{ }^{-}-[\partial \mathrm{t}]_{\mathrm{N}} \\
& \text { b. }\left[[\text { frail }]_{A} \text { ty }\right]_{N}-\left[[\text { jealous }]_{A} y\right]_{N} \\
& {\left[[\text { earth }]_{N} l y\right]_{A}-\left[[\text { earth }]_{N} y\right]_{A}} \\
& {\left[[\text { pig }]_{N} \text { let }\right]_{N}-\left[[\text { midge }]_{N} e t\right]_{N}}
\end{aligned}
$$

The generalization is then that suffix pairs $C_{i} X, X$ which have identical morphosyntactic properties neutralize after stem-final $\mathrm{C}_{\mathrm{i}}$ : only $\mathrm{X}$ appears. ${ }^{30}$ As a result, the constraint ${ }^{*} \mathrm{C}_{\mathrm{i}} \mathrm{C}_{\mathrm{i}}$ is always satisfied for the suffixes in (53). If no relevant suffix exists, fusion does not occur resulting in surface geminates as in $(54) .^{31}$

A third phonological condition for cohesion is illustrated in (56). Again, the suffixes form a single domain of syllabification together with the stem.

$$
\begin{aligned}
& {\left[[\mathrm{fly}]_{\text {STEM }}[\mathrm{t}]_{\text {HEAD SUFFIX }}\right]_{\text {WORD }} \rightarrow(\mathrm{fly}+\mathrm{t})_{\omega} \text { 'flight' }} \\
& {\left[[\mathrm{ten}]_{\text {STEM }}[\mathrm{th}]_{\text {HEAD SUFFIX }}\right]_{\text {WORD }} \rightarrow(\mathrm{ten}+\mathrm{th})_{\omega} \text { 'tenth' }} \\
& {\left[[\text { girl }]_{\text {STEM }}[\mathrm{s}]_{\text {HEAD SUFFIX }}\right]_{\text {WORD }} \rightarrow(\text { girl }+\mathrm{s})_{\omega} \text { 'girls' }}
\end{aligned}
$$

Assuming that a syllable must have a nucleus (arguably a HeADEDNEss effect), that obstruents cannot function as a syllable nucleus in English, and that all segments must be parsed into syllables, the integration of the suffixes in (56) into the pword of the stem can be described in terms of the domination of alignment constraints by phonological markedness constraints.

\subsubsection{Word plus clitic}

The evidence from boundary effects consistently shows that function words are not regularly integrated into the pword of the stem.

\footnotetext{
${ }^{30}$ The same generalization holds for German. For instance, the highly productive and etymologically unrelated adjectival suffixes [lıç] -lich and [Iç] -ig neutralize after [1]: only [Iç] -ig appears (e.g. Öl 'oil' + [lıç] - [ıç] $\rightarrow o ̈[$ lıç] (*öl. [lıç]) 'ölig' 'oily').

${ }^{31}$ Adverbial $-l y$ does, however, regularly cohere after stem-final $l$ preceded by schwa (e.g. $\operatorname{sim} p[\partial \mathrm{l}]+l y \rightarrow$ $\left.\left(\operatorname{sim}[\mathrm{pl}]_{\mathrm{y}}\right)_{\omega}\right)$, which distinguishes this suffix from the other suffixes in (54) (e.g. o[pan.n]ess '(open) $)_{\omega}$ ness'). Conceivably, the relevant property here is the CV-shape of $-l y$. For Swedish there is clear evidence that $\mathrm{CV}$-suffixes like - ma, - ga (where $\mathrm{C}$ is noncoronal) regularly cohere whereas CVC-suffixes like -bar do not cohere.
} 


$$
\begin{aligned}
& \text { [áim] } \left.]_{\text {WORD }}[\text { to }]_{\text {HEAD FW }} \rightarrow \text { (áim) }\right)_{\omega} \text { to 'aim to' }
\end{aligned}
$$

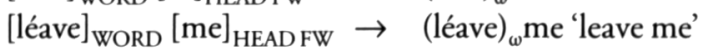

$$
\begin{aligned}
& {[\text { pút }]_{\text {WORD }}[\mathrm{it}]_{\text {HEAD FW }} \rightarrow(\text { pú }[\mathrm{r}])_{\omega} \text { it 'put it' }}
\end{aligned}
$$

The last example is in fact inconclusive because all consonants weaken before a stressless vowel, whether or not a pword boundary intervenes. Evidence for the non-integration of function words, as opposed to suffixes, into the pword of the stem comes from the behavior of the final consonant under stress. When a suffix as in $(58 a)$ is stressed because of further suffixation, aspiration applies, which indicates prosodic integration. By contrast, the flap remains before vowel-initial function words, regardless of (contrastive) stress (indicated by capitals in $(b)$ ), which indicates non-integration:

$$
\begin{aligned}
& \text { a. }\left[[\text { fát }]_{\text {STEM }}[\mathrm{al}]_{\text {HEAD SUFFIX }}\right]_{\text {WORD }} \rightarrow(\text { fá }[r] a l)_{\omega} \text { 'fatal' } c f . \text { (fa }\left[\mathbf{t}^{\mathrm{h}}\right] \text { álity) } \\
& \text { b. [pút } \left.]_{\text {WORD }}[\mathrm{it}]_{\mathrm{HEAD} \mathrm{FW}} \rightarrow(\text { pú }[\mathbf{r}])_{\omega} \text { it 'put it' cf. (pú[r]) }\right)_{\omega} \mathrm{IT}
\end{aligned}
$$

The patterns in (58) indicate that Align (Word,R; $\omega, \mathrm{R}$ ), as opposed to Align (Stem, $\mathrm{R} ; \omega, \mathrm{R})$, is not dominated by ONSET. Assuming that the morphosyntactic structures in (58) are correct this observation entails that words with nonintegrated suffixes like shyness must be represented prosodically as $\left((\operatorname{shy})_{\omega} \text { ness }\right)_{\omega}$. This structure violates the constraint NonRECURSIVITY, which prohibits the domination of pwords by pwords (cf. Selkirk 1995: 443). This conclusion can perhaps be avoided by some alternative analysis but will be accepted for now.

The observation that function words are not integrated into the pword of the preceding word to satisfy ONSET is part of the larger generalization that there is no phonologically conditioned cohesion across syntactic word (as opposed to stem) boundaries. (Historical) $\mathrm{HFF}$ as in (59) is fairly common.

$$
\begin{array}{ll}
{\text { (give } \left.)_{\omega} \text { me }>\text { (gimme) }\right)_{\omega}} & \text { cf. (*simme) '[sieve me] some flour' } \\
(\text { want })_{\omega} \text { to }>\text { (wanna) }{ }_{\omega} & \text { cf. (*planna) '[plan to] go' } \\
(\text { let })_{\omega} \text { us }>\text { (let's) }{ }_{\omega} & \text { cf. ('get's) '[get us] some tea' }
\end{array}
$$

\subsubsection{Summary}

In this section I have presented evidence that the pword structure of English words can be described on the basis of independently motivated morphosyntactic structure with no need for diacritic marking of affixes. Some representative examples are repeated in (6o):

$$
\begin{aligned}
\text { a. } & {[\text { not }]_{\text {MOD FW }} } \\
\text { b. } & {\left[[\mathrm{un}]_{\text {MOD PREFIX }}[\text { áble }]_{\text {WORD }}\right]_{\text {WORD }} } \\
& {\left[[\mathrm{im}]_{\text {MOD PREFIX }}[\text { mórtal }]_{\text {WORD }}\right]_{\text {WORD }} } \\
& {\left.[\text { but }]_{\text {HEAD FW }}[\mathrm{new}]_{\text {STEM }}\right]_{\text {WORD }} } \\
& {\left[[\text { re }]_{\text {HEAD PREFIX }}[\text { áble }]_{\text {STEM }}\right]_{\text {WORD }} } \\
\text { c. } & {\left[[\text { en }]_{\text {HEAD PREIX }}[\text { al }\right.} \\
& {\left[[\text { góal }]_{\text {STEM }}[\text { less }]_{\text {HEAD SUFFIX }}\right]_{\text {WORD }} }
\end{aligned}
$$

$$
\begin{aligned}
& \rightarrow{\text { (not })_{\omega} \text { 'not' }} \\
& \rightarrow(\text { ùn })_{\omega}(\text { áble })_{\omega} \text { 'unable' } \\
& \rightarrow(\text { im })_{\omega}(\text { mórtal })_{\omega} \text { 'immortal' } \\
& \rightarrow(\text { but })_{\Sigma} \text { 'but' } \\
& \left.\rightarrow(\text { re })_{\Sigma} \text { néw) }\right)_{\omega} \text { 'renew' } \\
& \left.\rightarrow(\text { (góale })_{\omega} \text { less }\right)_{\omega} \text { 'goalless' }
\end{aligned}
$$




$$
\begin{array}{ll}
{\left[\text { góal }_{\text {STEM }}[\text { íe }]_{\text {HEAD SUFFIX }}\right]_{\text {WORD }}} & \rightarrow \text { (góalie) })_{\omega} \text { 'goalie' } \\
{[\text { pút }]_{\text {WORD }}[\text { it }]_{\text {HEAD FW }}} & \rightarrow(\text { pú }[\mathrm{r}])_{\omega} \text { it 'put it' }
\end{array}
$$

Systematic cases of affix cohesion, boldfaced above, are described in terms of the domination of alignment constraints by phonological markedness constraints. All prosodic units satisfy constraints on prosodic domination including HEADEDNESs and Containment.

The distinction between cohering and noncohering affixation illustrated in (60) plays a crucial role in English morphophonology. Specifically, in native word formation only cohesive affixation exhibits stem-allomorphy (cf. (6ia)), stem selection (cf. $(6 \mathrm{I} b))$, and phonologically conditioned gaps (cf. $(6 \mathrm{I} c)) .{ }^{32}$

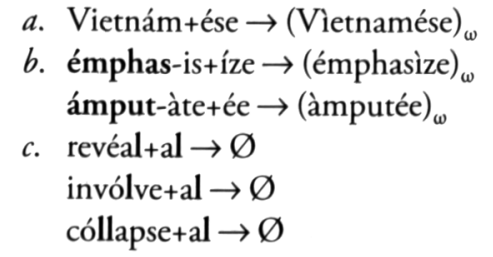

$$
\begin{aligned}
& \text { ballóon+líke } \rightarrow(\text { ballóon })_{\omega}(\text { like })_{\omega} \\
& \text { cúri-ous }+ \text { ness } \rightarrow\left((\text { cúrious })_{\omega} \text { ness }\right)_{\omega} \\
& \text { shóv-el }+ \text { ful } \rightarrow\left((\text { shovel })_{\omega} \text { ful }\right)_{\omega} \\
& \text { goal+less } \rightarrow\left((\text { goal })_{\omega} \text { less }\right)_{\omega} \\
& \text { leaf+let } \rightarrow\left((\text { leaf })_{\omega} \text { let }\right)_{\omega} \\
& \text { law }+ \text { ful } \rightarrow\left((\text { law })_{\omega} \text { ful }\right)_{\omega}
\end{aligned}
$$

Stem-allomorphy results when phonological markedness constraints are satisfied at the expense of violating PU constraints. 'Stress shift' in (6Ia) satisfies *CLASH but violates PU. No such allomorphy exists in noncohesive affixation. ${ }^{33}$

Similarly, (boldfaced) stem selection in $(6 \mathrm{I} b)$ satisfies phonological markedness constraints (i.e. OCP-constraints) at the expense of violating the constraint SuBCAT WORD, which requires affixes to combine with free stems (cf. Raffelsiefen $(2004 a, b))$. SuBCAT ${ }^{\text {WORD }}$ is never violated in noncohesive word formation. ${ }^{34}$

Finally, phonologically conditioned gaps as in (6Ic) result when an affix is required to satisfy both phonological markedness constraints and PU constraints. The gap in (6Ic) results from the fact that noun-forming -al-suffixation satisfies the constraint $\mathrm{L}_{\mathrm{i}} \mathrm{L}_{\mathrm{i}}$, which prohibits the co-ocurrence of identical liquids within the same pword. No such effect occurs in noncohesive affixation. The morphophonological differences between cohesive and noncohesive affixation illustrated in (6I) result directly from the rules for aligning morphosyntactic with prosodic boundaries. This is because the prosodic boundaries delimit the domains within which phonological markedness constraints are evaluated.

In addition to explaining restrictions on morphophonological phenomena as in (6I) the contrast between cohesive versus noncohesive affixation is also crucial to explaining restrictions on affix ordering. The generalization is that noncohesive der-

${ }^{32}$ For detailed discussion of these cases see Raffelsiefen (1999b, 2004a, b).

33 The sort of stress shift resulting from the 'rhythm rule' across pword boundaries in cases like thirteen mén differs from the pword-internal shift in $(6 \mathrm{I} a)$ in that stressless syllables never reduce to schwa ( $\sqrt{\text { Vietn[a] }}$ mése, but ${ }^{*}$ thirt [a]n mén)

34 This claim is consistent with the fact that bound stems can arise historically if the base of an established affixed word becomes obsolete as in ruthless, †ruth, doleful, $\uparrow$ dole. 
ivational suffixes cannot be followed by cohesive ones but the reverse order is possible (e.g. ${ }^{*}\left((\text { kind })_{\omega} \text { ness }\right)_{\omega}+$ ish versus $\left.\sqrt{ }\left((\text { monk }+ \text { ish })_{\omega}+\text { ness }\right)_{\omega}\right)$. Similarly, noncohesive prefixes cannot be preceded by cohesive ones but the reverse order is possible.

Independent motivation for the domain analysis illustrated in (60) is important in that a significant share of 'identity effects', including the cases in (62), results from noncohesion and should therefore not be cited as evidence for PU:

(62) vowel length in both $\left(\operatorname{sh}\left[\hat{a}^{+1} \mathrm{I}\right]\right)_{\omega}$ 'shy' and $\left.\left(\left(\operatorname{sh}\left[\mathrm{a}^{+1} \mathrm{I}\right]\right)_{\omega}{ }_{\omega}{ }{ }\right)\right)_{\omega}$ 'shyness'

aspiration in both $\left(\left[\mathrm{k}^{\mathrm{h}}\right] \text { ombine }\right)_{\omega}$ 'combine' and $(\mathrm{re})_{\omega}\left(\left[\mathrm{k}^{\mathrm{h}}\right] \text { ombine }\right)_{\omega}$ 'recombine'

cluster simplification in both (to $[\mathrm{m}(\mathrm{b})])_{\omega}$ 'tomb' and (to[m(b)] $)_{\omega}$ less) ${ }_{\omega}$ 'tombless'

cluster simplification in both $([(\mathrm{k}) \mathrm{n}] \mathrm{it})_{\omega}$ ' $\mathrm{knit}$ ' and $\left((\mathrm{be})_{\Sigma}[(\mathrm{k}) \mathrm{n}] \mathrm{it}\right)_{\omega}$ 'beknit'

Apart from the fact that it is superfluous to invoke PU to account for the phenomena in (62) there are arguments against doing so. Those are reviewed in the next section.

\subsection{EMPIRICAL DIFFERENCES BETWEEN}

\section{BOUNDARY EFFECTS AND PU EFFECTS}

\subsection{Real versus apparent violation of canonical phonology}

The distinct conditions pertaining to boundary effects versus PU effects to be reviewed below result from the property noted earlier that only PU effects involve genuine violations of regular phonology. A few examples will illustrate this point further. English shares with many other languages a window restriction on stress, which must not fall to the left of the antepenultimate syllable (e.g. hippopótamus, not *hippópotamus, mahógany not * máhogany). Assuming the mapping of the morphosyntactic to prosodic structures in (63), the relevant constraint is violated in (63a) but not in $(63 b)$. This is because the relevant point from which to compute the window restriction on stress is the (innermost) right pword boundary.

$$
\begin{aligned}
& \text { a. }\left[[\text { vínegar }]_{S T E M}[\text { ish }]_{\text {HEAD SUFFIX }}\right]_{\text {WORD }} \rightarrow \text { (vínegarish) }_{\omega} \\
& {\left[\text { cándidat }_{\text {STEM }}[\text { ure }]_{\text {HEAD SUFFIX }}\right]_{\text {WORD }} \rightarrow{\text { (cándidature })_{\omega}}} \\
& \left.[\text { président }]_{\text {STEM }}[y]_{\text {HEAD SUFFIX }}\right]_{\text {WORD }} \rightarrow \text { (présidency) }_{\omega} \\
& \left.[\text { dífficult }]_{\text {STEM }}[y]_{\text {HEAD SUFFIX }}\right]_{\text {WORD }} \rightarrow \text { (dífficulty }_{\omega} \\
& \text { b. }\left[[\text { rádical }]_{\text {STEM }}[\text { ness }]_{\text {HEAD SUFFIX }}\right]_{\text {WORD }} \rightarrow\left((\text { rádical })_{\omega} \text { ness }\right)_{\omega} \\
& {\left[[\text { cítizen }]_{\text {STEM }}[\text { ship }]_{\text {HEAD SUFFIX }}\right]_{\text {WORD }} \rightarrow\left((\text { cítizen })_{\omega} \text { ship }\right)_{\omega}} \\
& {\left[[\text { mónitor }]_{\text {WORD }}[\text { it }]_{\mathrm{FW}} \rightarrow{\text { (mónitor })_{\omega} \text { it }}\right.}
\end{aligned}
$$

The examples in $(63 a)$ versus $(63 b)$ illustrate two distinct sources of 'stress neutrality'. In (63a), regular restrictions on stress placement are violated to satisfy PU(sTrEss), a constraint which requires the stress in the derived word to correspond to the stress 
in the base. In $(63 b)$, stress placement in the complex structures is determined by the relevant domain boundaries. The correspondence to the stress in the respective base could be explained in terms of identical domain structures without invoking PU.

The second example illustrating the claim that only PU effects, but not boundary effects, violate regular phonology concerns the distribution of the velar nasal and (historical) [g]-loss in English. After [n], [g] is regularly deleted as in (64a) unless it precedes a segment more sonorous than [n] (i.e. vowel, liquid, glide) as in (64b) (cf. Kahn 1976: $130 \mathrm{ff}$.).

$$
\begin{aligned}
& \text { a. } \operatorname{ri}[\mathrm{ng}]>\operatorname{ri}[\mathrm{n}] \text { 'ring' } \\
& \text { tu[ngs]ten }>\text { tu[n.s]ten 'tungsten' } \\
& \mathrm{a}[\mathrm{ngz}] \text { iety }>\mathrm{a}[\mathrm{n} . \mathrm{z}] \text { iety 'anxiety' } \\
& \text { I[ngv]aeonic > I[y.v]aeonic 'Ingvaeonic' } \\
& \text { b. Mo[n.góu]lia 'Mongolia' } \\
& \text { fi[n.ga]r }\left({ }^{*} f i[n] e r\right) \\
& \text { ga[n.gl]ing }\left({ }^{*} \mathrm{ga}[\mathrm{nl}] \text { ing }\right) \\
& \text { hu[n.gr]y }\left({ }^{*} h u[\mathrm{gr}] \mathrm{y}\right) \\
& \mathrm{A}[\mathrm{ngm}] \text { ering }>\mathrm{A}[\mathrm{n} \cdot \mathrm{m}] \text { ering 'Angmering' } \\
& \text { li[n.gw]al }\left({ }^{*} \mathrm{li}[\mathrm{nw}] \mathrm{al}\right)
\end{aligned}
$$

Assuming that there are constraints which force onset syllabification of consonants followed by segments with higher sonority the stability of $[\mathrm{g}]$ in $(64 b)$ indicates the constraint ranking in $(65)$, where ONSET: ${ }^{*} y$ prohibits the occurrence of $[\mathrm{y}]$ in onset position. ${ }^{35}$

$$
\text { ONSET: }{ }^{*} \eta \gg{ }^{*} \mathrm{ng}
$$

Given the prosodic structures in (66) ONSET: ${ }^{*}[\mathrm{n}]$ is violated in $(66 a)$, but not in (66b). This is because phonetically, all pword-final consonants are necessarily associated with coda position to satisfy CONTAINMENT.

$$
\begin{aligned}
& \text { a. }\left[[\text { síng }]_{\text {STEM }}[\mathrm{er}]_{\text {HEAD SUFFIX }}\right]_{\text {WORD }} \rightarrow(\text { sí }[\mathrm{n}] \mathrm{er})_{\omega} \text { 'singer' } \\
& {\left[[\text { síng }]_{\text {STEM }}[\mathrm{ing}]_{\text {HEAD SUFFIX }}\right]_{\text {WORD }} \rightarrow(\text { sí[n]ing })_{\omega} \quad \text { 'singing' }} \\
& {\left[[\text { síng }]_{\text {STEM }}[\text { able }]_{\text {HEAD SUFFIX }}\right]_{\text {WORD }} \rightarrow(\text { sí[n]able })_{\omega} \quad \text { 'singable' }} \\
& {\left[[\text { lóng }]_{\text {STEM }}[\text { ish }]_{\text {HEAD SUFFIX }}\right]_{\text {WORD }} \rightarrow \text { (ló[y]ish) } \omega_{\omega} \text { 'longish' }} \\
& \text { b. }\left[[\text { ríng }]_{\text {WORD }}[\text { léader }]_{\text {WORD }}\right]_{\text {WORD }} \rightarrow(\text { rí[n] })_{\omega}(\text { lèader })_{\omega} \text { 'ring leader' } \\
& {\left[[\text { ríng }]_{\text {WORD }}[\text { líke }]_{\text {HEAD SUFFIX }}\right]_{\text {WORD }} \rightarrow(\text { rí[n] })_{\omega}(\text { like })_{\omega} \text { 'ringlike' }} \\
& {\left[[\text { ríng }]_{\text {TEM }}[\text { less }]_{\text {HEAD SUFFIX }}\right]_{\text {WORD }} \rightarrow\left((\text { rí }[\mathrm{y}])_{\omega} \text { less }\right)_{\omega} \text { 'ringless' }}
\end{aligned}
$$

\subsubsection{Generality of boundary effects versus affix-specificity of PU effects}

It has been demonstrated in $\mathbf{5 . 9 . 3}$ that pwords identified on the basis of syllablerelated diagnostics can be described without referring to individual affixes. Assuming

\footnotetext{
35 Kahn's (1976) description is misleading when he notes that liquids and glides tolerate preceding [ng]. Instead these segments require $[\mathrm{gg}]$ (rather than [ $\mathrm{g}]$ ). The pronunciation $\mathrm{E}[\mathrm{g}]$ lish instead of canonical $\mathrm{E}[\mathrm{ng}]$ lish is a PU effect based on E[n]land, where $[\mathrm{g}]$-loss is a boundary effect (cf. [[Eng $]_{\text {STEM }}[\text { land }]_{\text {HEAD }}$ suFFIX $]_{\text {WORD }} \rightarrow\left((E[\mathrm{~g}])_{\omega} \text { land }\right)_{\omega^{*}}$. The variant $(\mathrm{E}[\mathrm{ng}] \text { land })_{\omega}$ results from HFF (cf. (Lo[ng]Island) 'Long Island').
} 
the inviolability of CONTAINMENT it follows that non-integrated affixes are necessarily stress-neutral. This is because feet are necessarily contained within pwords and cannot incorporate pword-external syllables after affixation. Stress-neutrality is indeed a property of all consonant-initial suffixes in English. ${ }^{36}$

(67)

$\left[[\text { rádical }]_{\text {STEM }}[\text { ness }]_{\text {HEAD SUFFIX }}\right]_{\text {WORD }}$
$\left[[\text { devélop }]_{\text {STEM }}[\text { ment }]_{\text {HEAD SUFFIX }}\right]_{\text {WORD }}$
$\left[[\text { méaning }]_{\text {STEM }}[\text { less }]_{\text {HEAD SUFFIX }}\right]_{\text {WORD }}$
$\left.[\text { [púrpose }]_{\text {STEM }}[\text { ful }]_{\text {HEAD SUFFIX }}\right]_{\text {WORD }}$
$\left[[\text { offícial }]_{\text {STEM }}[\text { dom }]_{\text {HEAD SUFFIX }}\right]_{\text {WORD }}$
$\left[[\text { frólic }]_{\text {STEM }}[\text { some }]_{\text {HEAD SUFFIX }}\right]_{\text {WORD }}$
$\left[[\text { párrot }]_{\text {STEM }}[\text { let }]_{\text {HEAD SUFFIX }}\right]_{\text {WORD }}$
$\left[[\text { ínstant }]_{\text {STEM }}[\text { ly }]_{\text {HEAD SUFFIX }}\right]_{\text {WORD }}$
$\left[[\text { síngle }]_{\text {STEM }}[\text { ton }]_{\text {HEAD SUFFIX }}\right]_{\text {WORD }}$
$\left[[\text { súbtle }]_{\text {STEM }}[\text { ty }]_{\text {HEAD SUFFIX }}\right]_{\text {WORD }}$
$\left[[\text { únder }]_{\text {STEM }}[\text { ling }]_{\text {HEAD SUFFIX }}\right]_{\text {WORD }}$
$\left[[\text { héaven }]_{\text {STEM }}[\text { ward }]_{\text {HEAD SUFFIX }}\right]_{\text {WORD }}$
$\left[[\text { néighbor }]_{\text {STEM }}[\text { hood }]_{\text {HEAD SUFFIX }}\right]_{\text {WORD }}$

$$
\begin{aligned}
& \rightarrow\left((\text { rádical })_{\omega} \text { ness }\right)_{\omega} \\
& \rightarrow\left((\text { devélop })_{\omega} \text { ment }\right)_{\omega} \\
& \rightarrow\left((\text { méaning })_{\omega} \text { less }\right)_{\omega} \\
& \rightarrow\left((\text { púrpose })_{\omega} \text { ful }\right)_{\omega} \\
& \rightarrow\left((\text { offícial })_{\omega} \text { dom }\right)_{\omega} \\
& \rightarrow\left((\text { frólic })_{\omega} \text { some }_{\omega}\right)_{\omega} \\
& \rightarrow\left((\text { párrot })_{\omega} \text { let }\right)_{\omega} \\
& \left.\rightarrow\left((\text { ínstant })_{\omega}\right)_{\omega}\right)_{\omega} \\
& \rightarrow\left((\text { síngle })_{\omega} \text { ton }\right)_{\omega} \\
& \rightarrow\left((\text { súbtle })_{\omega} \text { ty }\right)_{\omega} \\
& \rightarrow\left((\text { únder })_{\omega} \text { ling }\right)_{\omega} \\
& \rightarrow\left((\text { héaven })_{\omega} \text { ward }_{\omega}\right. \\
& \rightarrow\left((\text { néighbor })_{\omega} \text { hood }{ }^{37}\right)_{\omega}
\end{aligned}
$$

By contrast, integrated affixes may or may not be stress-neutral (cf. Raffelsiefen 1996, 1999b). Compare the vowel-initial nominal suffixes -ity and -acy, both of which are integrated into the pword of stem to satisfy ONSET. 'Stress shift' in (68a) to satisfy *LAPSE defined in ( 5$)$, versus 'stress-neutrality' in $(68 b, c)$ to satisfy PU(sTress) with respect to the corresponding words in the righthand column, are idiosyncratic properties of the respective suffixes. ${ }^{38}$

$$
\begin{aligned}
& \text { a. }\left[[\text { rádical }]_{\text {STEM }}[\text { ity }]_{\text {HEAD SUFFIX }}\right]_{\text {WORD }} \rightarrow \text { (ràdicálity) }_{\omega} \\
& {\left[[\text { úrban }]_{\text {STEM }}[\text { ity }]_{\text {HEAD SUFFIX }}\right]_{\text {WORD }} \rightarrow \text { (urbánity) }_{\omega}} \\
& {\left[[\text { béllicòse }]_{\text {STEM }}[\text { ity }]_{\text {HEAD SUFFIX }}\right]_{\text {WORD }} \rightarrow \text { (bèllicósity) }_{\omega}} \\
& \text { b. } \left.\left.[\text { áccur }]_{\text {STEM }}[\text { acy }]_{\text {HEAD SUFFIX }}\right]_{\text {WORD }} \rightarrow \text { (áccuracy) }\right)_{\omega} \text { áccurate } \\
& {\left[[\text { ádequ }]_{\text {STEM }}[\text { acy }]_{\text {HEAD SUFFIX }}\right]_{\text {WORD }} \rightarrow \text { (ádequacy) }_{\omega} \text { ádequate }} \\
& {\left[[\text { móder }]_{\text {STEM }}[\text { acy }]_{\text {HEAD SUFFIX }}\right]_{\text {WORD }} \rightarrow \text { (móderacy) }_{\omega} \text { móderate }}
\end{aligned}
$$

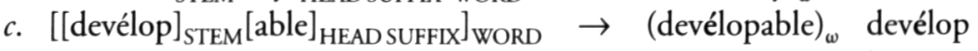

$$
\begin{aligned}
& {\left[[\text { límit }]_{\text {TEM }}[\text { able }]_{\text {HEAD SUFFIX }}\right]_{\text {WORD }} \rightarrow(\text { límitable })_{\omega} \text { límit }} \\
& {\left[[\text { ségreg }]_{\text {STEM }}[\text { able }]_{\text {HEAD SUFFIX }}\right]_{\text {WORD }} \rightarrow{\text { (ségregable })_{\omega}} \text { ségregàte }}
\end{aligned}
$$

Similarly, the cohesive adjectival suffixes $-i c$ and -ish differ in that FTBIN dominates PU(sTRESs) for -ic (cf. 69a) whereas the opposite ranking holds for -ish (cf. 69b).

${ }^{36}$ I assume that the stress in insightful is due to HFF (i.e. (insightful) $)_{\text {). }}$

37 The stability of the foot on the suffix in neighborhood (as opposed to the other suffixes in (67)) is not a HEADEDNESs effect but rather is necessary to satisfy a constraint which requires $h$ to align with a left foot or pword boundary (cf. Raffelsiefen 1999b, 2004a).

${ }^{38}$ It is irrelevant for the point under discussion whether the suffix is analyzed as -acy, which selects (truncated) stems, or just $-y$, which causes spirantization of the stem-final consonant). Importantly, accuracy differs from urbanity in that it ends in three unstressed syllables, a structure unattested in simplexes. 
(69)

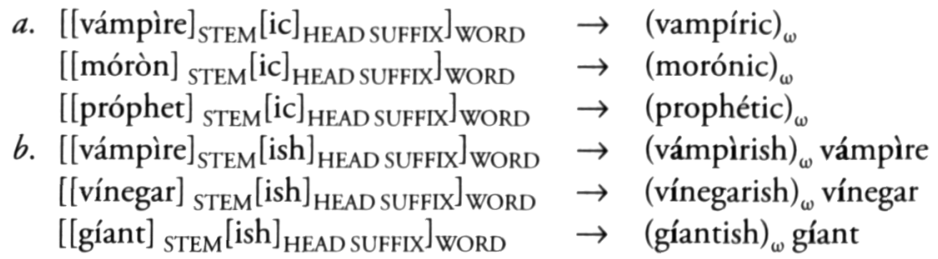

'Rightward stress shift' in cohesive suffixation is possible because the formation of feet that span both stem and suffix syllables does not violate ConTAINMENT (e.g. $\left.\left((\text { ràdi })_{\Sigma}(\text { cálity })_{\Sigma}\right)_{\omega}\right)$. This possibility is excluded for noncohesive affixes. The relevant generalization is missed by Benua (1997a), where all affixes are diacritically assigned to some class to account for stress behavior.

TCT [Transderivational Correspondence Theory RR] accounts for affix class behavior without representational or serial assumptions. Both kinds of affixes can be prosodically integrated into the stem, and all words can be derived in parallel, without intermediate stages. The differences between class I and class 2 words follow from the rank of identity constraints on two distinct OO [output-output RR]-correspondence relations. Benua (I997a: 169)

The description of morphophonology based on affix-class advocated by Benua not only misses the generalization that 'neutrality' can in many cases be predicted on the basis of the phonological form of the suffix but also falsely implies that all types of 'non-neutral' morphophonology can be subsumed under some unique constraint ranking. ${ }^{39}$

Consider next the evidence from the velar nasal, which on the domain analysis cannot be followed by $g$ before non-cohering suffixes. The relevant words include suffixes with initial liquids or glides (cf. the data in $(64 b)$ ), which in fact, are never preceded by $[\mathrm{ng}]$ :

$$
\begin{aligned}
& \left.\left[[\text { fáng }]_{\text {STEM }}[\text { less }]_{\text {HEAD SUFFIX }}\right]_{\text {WORD }} \rightarrow\left((\text { fá }[\mathrm{n}])_{\omega}\right)_{\omega} \text { less }\right)_{\omega} \text { 'fangless' }
\end{aligned}
$$

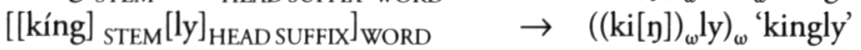

$$
\begin{aligned}
& \text { [[yóung } \left.]_{\text {STEM }}[\text { ling }]_{\text {HEAD SUFFIX }}\right]_{\text {WORD }} \rightarrow\left((\text { you }[n])_{\omega} \text { ling }\right)_{\omega} \text { 'youngling' } \\
& \left.\left[[\text { ríng }]_{\text {STEM }}[\text { let }]_{\text {HEAD SUFFIX }}\right]_{\text {WORD }} \rightarrow\left((\mathrm{ri}[\mathrm{n}])_{\omega}\right)_{\text {let }}\right)_{\omega} \text { 'ringlet' }
\end{aligned}
$$

By contrast, the extension of coda [ $\mathrm{n}]$ from a base into words with cohesive suffixes to satisfy PU (while violating *ONSET: ${ }^{*} \mathrm{y}$ ) is somewhat idiosyncratic. For agentive -er, PU dominates *ONSET: *n whereas for comparative -er, PU effects are unsystematic. Other cohesive suffixes exhibit similarly unpredictable behavior, where variation among speakers is common (cf. Wells I990a; OED). ${ }^{40}$

\footnotetext{
39 For instance the suffixes -ity and -acy would presumably both be assigned to Class I based on their association with stem-allomorphy, which raises the question of how to account for their distinct stress behavior. In fact, there is not a single pair of cohesive suffixes In English whose systematic morphophonological properties could be described exhaustively by some unique ranking of constraints (cf. Raffelsiefen $19996,2004)$.

${ }_{40}$ This is not to deny the existence of pervasive generalizations concerning the ranking of PU constraints including the fact that PU constraints are generally undominated for inflectional affixes in English.
} 
a. No PU effect (stró[ng]er) $)_{\omega}$ 'stronger'

(diphthó[ng]al) $)_{\omega}$ 'díphthongal'

b. PU effects

(díphtho[ng]ìze) $)_{\omega}$ ' díphthongize'

(sí[n]er) $)_{\omega}$ (cf. sí[n]) 'singer'

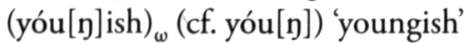

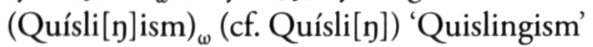

(hà[r]ée) $)_{\omega}(\mathrm{cf} . \mathrm{ha}[\mathrm{\eta}])$ 'hangée'

(Pèki[n]ése) ${ }_{\omega}$ (cf. Péki[n]) 'Pekingese'

(díphtho[n]ìze) ${ }_{\omega}(\mathrm{cf}$. díphtho[n]) 'díphthongíze'

\subsubsection{The relevance of the base}

Assuming the criteria for recognizing morphosyntactic structure specified in 5.9 .3 it follows that for head affixation, the syntactic status of the stem (i.e. free or bound) is irrelevant for prosodic structure. Recall that head prefixed words as in (72) are indeed prosodically indistinguishable, whether or not a base exists.

(72) [[be]head prefix [gét $\left.]_{\text {STEM }}\right]_{\text {WORD }}$

[[be]head prefix [gín $\left.]_{S T E M}\right]_{\text {WORD }}\left((\text { be })_{\Sigma} \text { gín }\right)_{\omega}$ 'begin'

In general it is expected that for head affixation boundary effects persist, whether or not the stem continues to correspond to an independently occurring word. This is because that sort of information is not reflected in the syntactic representation on which the prosodic structures are based. ${ }^{41}$ For instance, the syntactic representation of the -ful-suffixations in (73) does not encode the fact that dole became obsolete whereas soul continues to exist as an independent word. As a result of their identical morphosyntactic structures the words in (73) also have the same prosodic properties. In fact, the 'Final-C effect' in doleful has persisted after dole became obsolete.

$$
\begin{array}{ll}
{\left[[\text { sóul }]_{\text {STEM }}[\text { ful }]_{\text {HEAD SUFFIX }}\right]_{\text {WORD }}} & \left((s[\text { oul }])_{\omega} \text { ful }\right)_{\omega} \text { 'soulful' } \\
{\left[[\text { dóle }]_{\text {STEM }}[\text { ful }]_{\text {HEAD SUFFIX }}\right]_{\text {WORD }}} & \left((\mathrm{d}[\text { oul }])_{\omega} f u l\right)_{\omega} \text { 'doleful' }
\end{array}
$$

Recall that word-internal 'Final-C' effects are systematically eliminated as a result of 'HFF', and do not occur in simplexes. ${ }^{42}$ The systematic persistence of this boundary effect in noncohesive suffixation based on 'bound stems' therefore strongly supports the description of syntax to prosody mapping spelled out in s. 9.3. In general, suffixed words based on bound stems as in (74a) and those based on free stems as in (74b) are prosodically indistinguishable.

$$
\begin{aligned}
& \text { a. [oun.l]y 'only' } \\
& \text { (on) }{ }_{\omega} \mathrm{ly} \\
& \text { (gorm) }{ }_{\omega} \text { less } \\
& \text { b. 1[oun.l]y }
\end{aligned}
$$$$
\text { (lone) }{ }_{\omega} \text { ly }
$$

$$
\mathrm{h}[\mathrm{arm} . \mathrm{l} \text { ]ess }
$$$$
\text { (harm) })_{\omega} \text { less }
$$$$
\text { app[ont.m] ent (appoint) }{ }_{\omega} \text { ment }
$$

\footnotetext{
${ }^{41}$ Recall that head affixes by definition combine with 'stems'.

${ }^{42}$ The same sort of boundary effect can be observed in German (e.g. Kan [i:nç]en (Kanin) ${ }_{\omega}$ chen 'rabbit', where Kanin is a bound stem and [i:nç] could not occur in simplexes).
} 


\begin{tabular}{|c|c|c|c|}
\hline 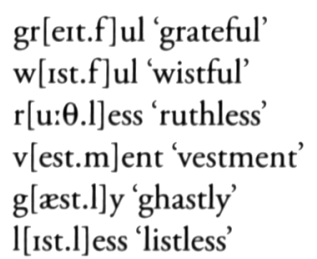 & $\begin{array}{l}\text { (grate) })_{\omega} \text { ful } \\
\text { (wist) }{ }_{\omega} \text { ful } \\
\text { (ruth) })_{\omega} \text { less } \\
\text { (vest) }{ }_{\omega} \text { ment } \\
\text { (ghast) }{ }_{\omega} \text { ly } \\
\text { (list) })_{\omega} \text { less }\end{array}$ & $\begin{array}{l}\mathrm{h}[\text { eit.f]ul } \\
\mathrm{f}[\mathrm{Ist} . \mathrm{f}] \mathrm{ul} \\
\mathrm{t}[\mathrm{u}: \theta .1] \mathrm{ess} \\
\text { inv[est.m]ent } \\
\mathrm{v}[\text { æest.l]y } \\
\mathrm{r}[\text { est.l]less }\end{array}$ & $\begin{array}{l}\text { (hate) })_{\omega} \text { ful } \\
\text { (fist) }{ }_{\omega} \text { ful } \\
\text { (tooth) })_{\omega} \text { less } \\
\text { (invest) }{ }_{\omega} \text { ment } \\
\text { (vast) })_{\omega} \text { ly } \\
\text { (rest) })_{\omega} \text { less }\end{array}$ \\
\hline
\end{tabular}

Similarly, Containment effects persist regardless of the occurrence of the stem as an independent word as is demonstrated in (75). Clearly, reckless, which is based on a bound stem, patterns prosodically with checkless, rather than with comparable simplexes.

$$
\begin{array}{lll}
a . & \text { re[k'.l]ess 'reckless' } & \text { (reck) }{ }_{\omega} \text { less } \\
\mathrm{fe}[\mathrm{k} \cdot . \mathrm{l}] \mathrm{ess} \text { 'reckless' } & \text { (feck) })_{\omega} \text { less } \\
\text { ha[p'.l] ess 'hapless' } & \text { (hap) })_{\omega} \text { less }
\end{array}
$$

b. che[k'.l]ess spe[k'.l]ess ma[p'.l]ess

$$
\begin{aligned}
& \text { (check) })_{\omega} \text { less } \\
& \text { (speck) })_{\omega} \text { less } \\
& \text { (map) })_{\omega} \text { less' }
\end{aligned}
$$

In general, noncohesive affixation based on bound stems is rare in English because noncohesive affixes are typically native, which means that the occurrence of bound stems presupposes simultaneous loss of some word $\mathrm{W}_{\mathrm{i}}$ and survival of a word historically derived from $\mathrm{W}_{\mathrm{i}}{ }^{43}$ Yet, the conclusion is clear: the question of whether the stem is 'free' or 'bound' is irrelevant for the occurrence of boundary effects in noncohesive suffixation. This is not to deny the crucial relevance of free stems for learning a head affix in the first place which was noted above. Recall that the prefix se-plays no role in English morpho(phono)logy because it is exclusively based on bound stems and therefore it is not learnable. Similarly, the historical diminutive head suffix - kin in English is no longer learnable, which accounts for the parsing of pumpkin as a single pword (76).

$$
\text { [púmpkin] }]_{\text {WORD }} \rightarrow \text { (púmpkin) }
$$

As a result of the parsing in (76) FINAL-C effects are prone to disappear. Wells (1990a) lists the pronunciations $p u[\mathrm{mpk}] i n, p u[\mathrm{nk}] i n$, where the former is probably a spelling pronunciation. ${ }^{44}$ No corresponding reduced variants are attested for any of the words exhibiting internal FINAL-C effects in (74). Crucially, these words differ from pumpkin in that they include an affix that also occurs with free stems and therefore is learnable.

${ }^{43}$ By contrast, for cohesive affixation, which is often non-native, there are additional sources for bound stems: $(a)$ often a word is borrowed without borrowing its etymological base as well (e.g. Old French haineus, mollifier, baptiser were borrowed into English (cf. heinous, mollify, baptize), but their respective bases were not (i.e. Old French haine 'hate', Latin mollis 'soft', Greek baptein 'to dip')); (b) cohesive, but not noncohesive, suffixes can select 'truncated' stems in native word formation (cf. (6Ib)).

44 Similarly, historical prosodic fusion of the words in (i) in German results from the fact that the suffix - der (probably related to English tree) occurred only with bound stems and was therefore no longer learnable:

(i) Older stages

Modern German

[[hólun $\left.]_{\text {TEM }}[\text { ter }]_{\text {HEAD SUFFIX }}\right]_{\text {WORD }} \rightarrow{\text { (hólun) })_{\omega} \text { ter }}$

$[\text { Holunder }]_{\text {WORD }} \rightarrow$ (Holúnder) $)_{\omega}$ 'elder'

$\left[[\text { wáchsol }]_{\text {STEM }}[\text { ter }]_{\text {HEAD SUFFIX }}\right]_{\text {WORD }} \rightarrow(\text { wáchsol })_{\omega}$ ter

$[\text { Wacholder }]_{\text {WORD }} \rightarrow$ (Wachólder) $)_{\omega}$ 'juniper' 
Turning now to PU effects in cohesive affixation, the occurrence of the relevant sound property in a free-standing word is crucial. Recall the violations of the ARAB rule in -ic-suffixation discussed in 5 . 9.I which are necessarily licensed by an independent word. Additional examples are given in (77).

$$
\begin{aligned}
& \text { (ph[óv]bic) })_{\omega} \text {-ph[óv]bia 'phobia' } \\
& \text { (sc[í: ]nic) } \omega_{\omega}-s c[i:] n e \text { 'scene' } \\
& \text { (phon[í: ]mic) } \omega_{\omega} \text { —phón[ì: ]me 'phoneme' }
\end{aligned}
$$

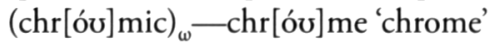

$$
\begin{aligned}
& \text { (am[í: ]bic) } \omega_{\omega}-\mathrm{am}[\mathrm{i}: \text { ] ba 'amoeba' }
\end{aligned}
$$

The relevance of a freestanding word for licensing PU effects can also be illustrated with stress. The (historically conditioned) stress on the preantepenultimate syllable in -able-suffixation tends to regularize as in (78a) unless it is 'licensed' by corresponding stress in an independent word as in $(78 b)$ :

$$
\begin{aligned}
\text { a. } & \text { (hóspitable })_{\omega}>(\text { hospítable })_{\omega} \\
& (\text { déspicable })_{\omega}>(\text { despícable })_{\omega} \\
& (\text { fórmidable })_{\omega}>(\text { formídable })_{\omega} \\
& (\text { ápplicable })_{\omega}>(\text { applícable })_{\omega}
\end{aligned}
$$
b. (cháritable) ${ }_{\omega}$ chárity
(inhéritable) ${ }_{\omega}$ inhérit
(médicable $)_{\omega}$ médicàte
(prácticable) ${ }_{\omega}$ práctice, práctical

The sensitivity to independent base words observed in (78) contrasts with noncohesive suffixation as in environment, where the 'unexpected' stress (the skipping of the closed penult) is stable even for speakers who are unfamiliar with environ as a freestanding word.

Additional support for the generalization established here comes from the phonology of the velar nasal. Recall the occurrence of [n] in cohesive suffixation as in si[n]er 'singer', belo[n]er 'belonger', which violates *ONSET: *n to satisfy PU. The dependence of this effect on licensing by an independent word is shown by the noun (war) mo[ng]er 'monger', whose historical base (i.e. Old English mangian 'to barter') became obsolete. There is good evidence that the agentive suffix -er continues to be recognized in this noun (cf. the acceptability of modification with continual as in continual liar, continual war monger, as opposed to * continual thief ). As has been demonstrated above, for noncohesive affixation recognition of the suffix suffices to secure boundary effects. ${ }^{45}$ By contrast, PU effects require licensing of the relevant feature by an independent word to be stable.

The data considered here indicate that the mere existence of a related word with some specific sound feature is not enough to license a PU effect. In addition, the words have to have a close semantic relation, which plausibly determines recognition of paradigm membership. This point can be illustrated further with the distribution of schwa

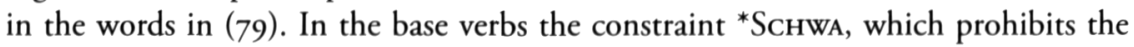
occurrence of schwa, is violated to satisfy a constraint on sonority sequencing. ${ }^{46} \mathrm{By}$

\footnotetext{
45 The claim is that for instance fa[n] less will remain $f a[n]$ less, even if fang becomes obsolete.

${ }^{46}$ For evidence that schwa deletes unless it is necessary to satisfy constraints see Raffelsiefen (1995, 2000). Hooper (1976) observes that in American English post-tonic schwa deletes if the preceding sound is
} 
contrast, in the suffixed forms violation of ${ }^{*}$ SCHWA is not motivated on phonological grounds but is necessary to satisfy PU. The occurrence of the relevant PU effect in the gerunds in (79a), but not in the (historical) gerunds in $(79 b)$, is determined by semantic relatedness. Specifically, the fact that the nouns in $(79 b)$ are unaffected by the relevant PU constraints results from the fact that their paradigm membership is not recognized due to semantic disassociation. Those cases are similar to cases like inkling, where schwa cannot be analogically extended because the base word has become obsolete (ink[ə]l'to hint').
a. (chuck([ə])ling) 'the act of chuckling' (tick([ə])ling) 'the act of tickling' (jugg([ə]) ling) ' the act of juggling'
b. (crackling) ' 'crisp skin of roast pork' (twinkling) $)_{\omega}$ 'an instant' (kindling) 'dry sticks of wood used to start a fire' (lightning) $\omega_{\omega}$ 'natural electric discharge in the atmosphere'

$$
\begin{aligned}
& \text { chuck[ə]l 'chuckle' } \\
& \text { tick[ə]l 'tickle' } \\
& \text { jugg[ə]l 'juggle' } \\
& \text { crack[ə]l 'crackle' } \\
& \text { twink[ə]l 'twinkle' } \\
& \text { kind[ə]l 'kindle' } \\
& \text { light[ə]n 'lighten' }
\end{aligned}
$$

Similarly, semantic drift in $(8 \mathrm{o} a)$ rules out the possibility of analogical leveling. By contrast PU effects are possible whenever there is a close semantic relationship to the base as is shown by the historical replacement of the lax vowels (cf. historical $o b[\mathrm{e}]$ sity) by tense vowels or diphthongs in $(80 b)$ :

$$
\begin{aligned}
& \text { a. (extr[e]mities) }{ }_{\omega} \text { 'hands or feet' } \\
& \text { (gr[æ] vity) })_{\omega} \text { 'force of gravitation' } \\
& \left(\mathrm{m}[\mathrm{I}] \text { serable) }{ }_{\omega}\right. \text { 'very bad' } \\
& \text { (f[æ]bulous) })_{\omega} \text { 'extremely pleasing' } \\
& \text { b. (ob[i: } \left.]_{\text {sity }}\right)_{\omega} \text { 'quality of being obese' } \\
& \text { (cons[ou]latory) }{ }_{\omega} \text { 'affording an } \\
& \text { instance of consoling' } \\
& \text { ([eI]pical) })_{\omega} \text { 'pertaining to the apex' [eI]pex 'apex' }
\end{aligned}
$$

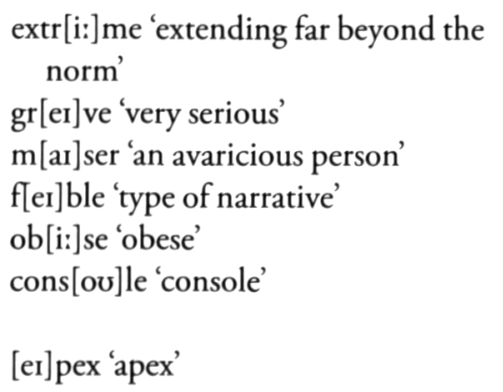

The irrelevance of semantic affinity for boundary effects in noncohesive affixation follows from the irrelevance of the status of the stem. ${ }^{47}$

\subsubsection{Prosodic consistency}

Analyzing the occurrences of stressed [i:] in phon[í]mic, $d[i:] c e n c y$, or $o b[i$ i: $]$ sity as PU effects has no implication for other sound properties in the relevant words. For

less sonorous than the following sound (e.g. év(e)ry, féd(e) ral, also the examples in (79)), but not vice versa (e.g. thérapy, cólony, also gerunds like quarreling), which indicates that the constraint prohibiting schwa is dominated by NoCoDA.

47 Consider also the existence of boundary effects in head prefixation in cases like reduce, prevent, deduct, etc. where semantic affinity plays no role. 
instance, PU(stress) may or may not be satisfied as well (e.g. PU(stress) satisfaction correlates in décency-décent, but not in phonémic-phónème). By contrast, the analysis of some sound property as a boundary effect necessarily implies correlating effects. Recall the discussion of the example shyness, where the analysis of vowel length as a pword-final boundary effect necessarily implies an 'initial' boundary effect for the following consonant (i.e. 'unexpected' fortition) and vice versa. This sort of mutual implication is referred to as 'prosodic consistency' here and will be used as follows to distinguish boundary effects from PU effects.

The Prosodic Consistency Criterion

If in a morphologically complex string a boundary analysis captures clusters of systematically correlating properties non-occurring in simplex words, each of these properties is to be analyzed as a boundary effect.

To illustrate the proposal in (8I) consider aspiration in the prefixed word in $(82 b)$, which could be analyzed as a PU effect licensed by word-initial aspiration in the base. Note that a stop between a stressed and an unstressed vowel is normally unaspirated in English as in (82a) (cf. Kahn 1976).

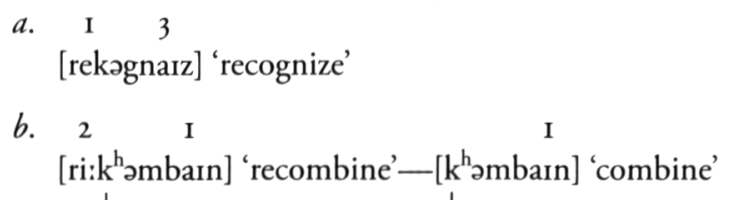

Given a domain analysis as described in 9.2.2 (based on $\left[[\mathrm{re}]_{\text {HEAD FW }}[\text { cogníze }]_{\text {STEM }}\right]_{\text {WORD }}$ and $\left[[\mathrm{re}]_{\text {MOD FW }}[\text { combíne }]_{\text {WORD }}\right]_{\text {WORD }}$ ) a PU analysis of aspiration would be ruled out by the Prosodic Consistency Criterion in (8I). This is because aspiration correlates systematically with other sound properties entailed by the pword structure in (83).
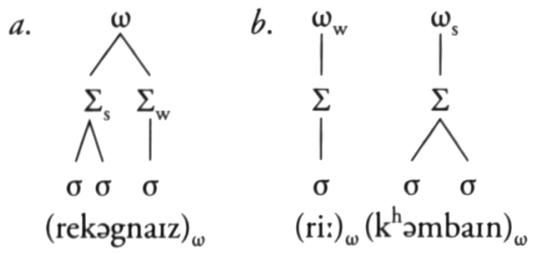

The lax vowel in the cohering CV-prefix in (83a) satisfies Trisyllabic Laxing and conforms entirely to the phonology found in corresponding position in simplex words (e.g. [é]lefant, $p$ [é] lican, $t$ [é]lephone). The non-cohering CV-prefix in $(83 b)$ satisfies the constraints on vowel quality and quantity determined by its pword status (cf. CV-content words such as (sí:) $)_{\omega}$ 'sea', (tí:) ${ }_{\omega}$ 'tea') to the effect that such vowels are non-occurring in the corresponding position in polysyllabic simplexes. The non-cohering prefix implies exclusive onset syllabification for the following stop, which causes aspiration in $(83 b)$. The analysis of aspiration as a boundary effect, and not a PU effect, in accord- 
ance with the Prosodic Consistency Criterion, entails and is supported by additional stress correlations. The strong-weak pattern in récognize conforms to the rule that in verbs with two feet, the final foot is weak if it does not branch (circumcise, réconcile, álternàte).$^{48}$ The weak-strong pattern in rècombine conforms to the rule that prefixes forming a separate pword in verbs and adjectives are always weak (cf. (32a)). The I-3 pattern in (82a), as opposed to the $2-\mathrm{I}$ pattern in $(82 b)$, follows from the distinct effects yielded by feet contained in a single pword (i.e. stronger contrast in relative prominence) as opposed to feet belonging to separate pwords. The observation that these correlating stress patterns could not be mimicked in terms of PU confirms the irrelevance of PU for the description of morphophonology in $(82 b)$.

\subsubsection{Sensitivity to speech register}

Whereas PU constraints by definition require identity of sound structure in related words, the sort of identity caused by satisfied alignment results from identical positions of speech sounds with respect to some domain boundary. For instance, there is no need to assume that glottalization of $t$ in nigh $\left[\mathrm{t}^{ }\right]$rate or doub $\left[\mathrm{t}^{\prime}\right]$ less motivates a PU constraint requiring phonetic identity to the corresponding stops in night and doubt, respectively. Rather, any $\underline{t}$ in syllable-final position will exhibit the relevant features.

The claim that identity effects resulting from noncohesive morphology differ in essence from identity effects resulting from PU constraints is supported by evidence from casual speech. Specifically, 'identity' resulting from noncohesion in some cases disappears, while boundary effects persist, a phenomenon which cannot be observed for PU effects. Compare the boundary effect in the slow and careful pronunciation nigh [ $\left.\mathrm{t}^{\prime}\right]$ owl (i.e. glottalization before a vowel), which could be mistaken for a PU effect licensed by independent nigh $\left[\mathrm{t}^{ }\right]$, with the boundary effect in the fast (or perhaps normal) pronunciation 'nigh[r]owl' (i.e. flapping before a stressed vowel). Persistence of the boundary effect results from the persistence of prosodic structure itself: the $t$ is in both pronunciations followed by a pword boundary and must therefore associate with the coda to satisfy ConTAInment. By contrast, while (certain) PU effects, including the schwa in chuck([ə]) ling discussed in (79), may disappear in fast speech, such a change results invariably in conformity to simplex phonology.

(84) The Casual Speech Criterion

If the fast or casual pronunciation of a morphologically complex string exhibits a sound property absent from comparable simplexes and distinct from the careful pronunciation of that string, that property is to be analyzed as a boundary effect.

\footnotetext{
${ }^{48}$ The fact that the final foot is strong if it ends in a cluster (còndescé [nd], circumvé[nt], rèprehé[nd]) indicates that stress is based on syllable structure. The last syllable in réconcile is open (recall that the pword-final consonant is syllabified as an onset in the lexicon) and therefore has a non-branching rhyme. The last syllable in condescénd is closed, that is, with a branching rhyme, which attracts main stress.
} 
To illustrate the Casual Speech Criterion with an additional example, compare the careful and the casual pronunciations of the German clitic structures in (85):

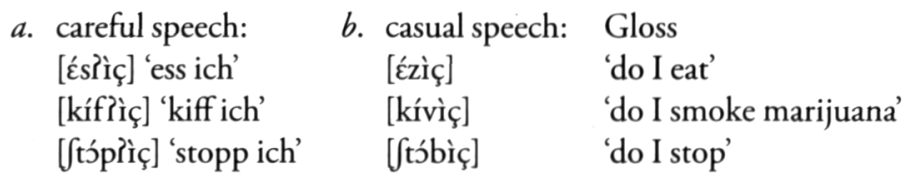

Significantly, the casual pronunciations violate a constraint against voiced obstruents following short stressed vowels in German, arguably a constraint prohibiting voiced ambisyllabic obstruents (cf. Becker 1998). There are a few lexical exceptions for stops (e.g. [ćbə] 'Ebbe' 'low tide') but none for fricatives. As a result of satisfying both conditions in (84) the voiced fricatives in $(85 b)$ must be analyzed as boundary effects. Obstruent voicing is indeed most plausibly analyzed in terms of persisting prosodic boundaries as is shown by the mapping in (86). In German, too, vowel-initial suffixes, but not clitics, cohere: ${ }^{49}$
a. $\left[\varepsilon^{\prime}\right]_{\text {WORD }}[\text { íç] }]_{\text {FUNCTION WORD }}$
$\rightarrow(\text { És })_{\omega}(\text { íç })_{\Sigma} \quad$ 'ess ich' 'do I eat'

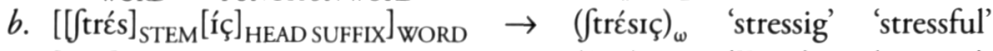
c. $\left[\varepsilon_{\text {SIç }}\right]_{\text {WORD }}$

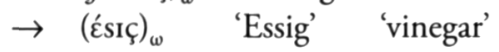

Arguably, the constraint against voiced ambisyllabic consonants, which accounts for the ungrammaticality—also in casual speech—of suffixed *[ftrézıç] (cf. (87b)) and simplex * [Ézıç] (cf. (87c)), is dominated by a constraint prohibiting voiceless ambisyllabic consonants in pword-final position (cf. $(87 a)$ ).

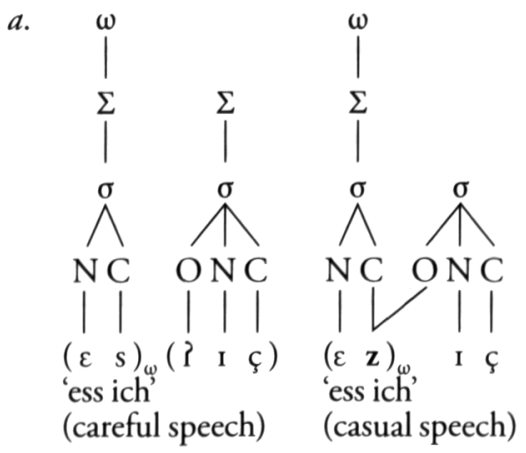

$b$.
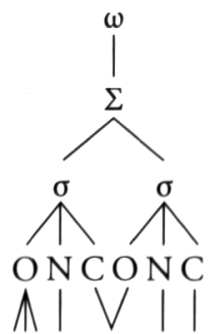

$\left(\int \operatorname{tr} \varepsilon \quad s \quad\right.$ I ç $)$

$*[$ treziç $]$

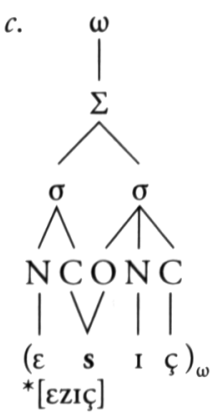

The German data show that boundary signals can be more salient in casual speech than in careful speech. That is, [źsıç] 'ess ich', a more careful pronunciation, is at least near-homophonous to the simplex [ésıç] 'Essig', whereas the more casual pronunciation [Ezíç] 'ess ich' differs markedly.

49 For a different analysis, see Hall (1999: I18 ff.) 


\subsection{CASE STUDIES: PU-EFFECTS \\ VERSUS BOUNDARY EFFECTS}

In s. 9.5.I I investigate various morphophonological effects discussed in the literature on $x$-tensing, to illustrate the application of some of the criteria in s.9.4. The focus of ss. 9.5.2 and 9.5.3 is on poorly motivated use of PU constraints.

\subsection{The case of $æ$-tensing}

In Philadelphia English the vowel $[\mathfrak{x}]$ and its tense counterpart $[\mathrm{E}]$ are (mostly) in complementary distribution. [E] appears before (phonetically) exclusively tautosyllabic voiceless fricatives or nasals other than $[\mathrm{y}]$ as in (88a), [æ] appears elsewhere (cf. Ferguson (1972)). In (88b), the segmental condition for $æ$-TENSING is not satisfied, in $(88 c)$ the syllabic condition is not satisfied.

$$
\begin{aligned}
& \text { a. b[E]n 'ban' } \\
& \text { st[E]ff' 'staff' } \\
& \text { b. } \mathrm{r}[æ \mathrm{n}] \mathrm{k} \text { 'rank' } \\
& \text { b[æt] 'bat' } \\
& \mathrm{m}[\mathrm{E}] \mathrm{s}[\$] \text { ter 'master' } \\
& \text { bl[æn]ket 'blanket' }
\end{aligned}
$$

Benua (I995: IO) describes this distribution in terms of the constraint ranking in (89):

$$
\mathfrak{x} \text {-TeNSING }{ }^{*} \text { TeNSE-LOW }
$$

The constraint *TENSE-LOw, which prohibits tense low vowels and accounts for vowel laxness in the 'elsewhere environment' (cf. $(88 b, \mathrm{c})$ ) ranks below $\mathfrak{x}$-Tensing, a constraint prohibiting lax [æ] before specific tautosyllabic consonants. Given this distribution, the occurrences of [E] qualify as PU effects in (90a), but not in (90b).

$$
\begin{aligned}
& \text { a. } \mathrm{b}[\hat{\mathrm{E}}] \text { nner 'banner (one who bans)' } \\
& \mathrm{c}[\mathrm{E}] \text { nnable 'cannable (can be canned)' } \\
& \mathrm{p}[\mathrm{E}] \text { ssée 'passee (one who is passed)' }
\end{aligned}
$$
b. har[É] ssment 'harassment' c[É]n òpener 'can opener' c[É]n it 'can it'

Specifically, given the prosodic structures in (9I) the occurrence of tense [E] satisfies $\mathfrak{x}$-tensing in $(9 \mathrm{I} b)$. This is because the consonant following $\mathfrak{a}$ is syllabified in coda position to satisfy Containment.

$$
\begin{aligned}
& \text { a. }\left[[\text { bán }]_{\text {STEM }}[\mathrm{er}]_{\text {HEAD SUFFIX }}\right]_{\text {WORD }} \rightarrow(\mathrm{b}[\text { É }] \text { nner })_{\omega} \quad \mathrm{cf} .(\mathrm{b}[\dot{x}] \text { nner })_{\omega} \\
& {\left[[\text { cán }]_{\text {STEM }}[\text { able }]_{\text {HEAD SUFFIX }}\right]_{\text {WORD }} \rightarrow(\mathrm{c}[\text { É }] \text { nnable })_{\omega} \quad \mathrm{cf.}(\mathrm{c}[\ddot{x}] \text { nnibal })_{\omega}} \\
& \left.[\text { páss }]_{\text {STEM }}[\text { ée }]_{\text {HEAD SUFFIX }}\right]_{\text {WORD }} \rightarrow\left(\mathrm{p}[\text { Ė]ssée })_{\omega} \quad \mathrm{cf.}(\mathrm{p}[\grave{\gtrless}] \text { ssé })_{\omega}\right. \\
& \left.b \text {. [haráss }]_{\text {STEM }}[\text { ment }]_{\text {HEAD SUFFIX }}\right]_{\text {WORD }} \rightarrow\left(\left(\text { har }[E ́]_{s s}\right)_{\omega} \text { ment }\right)_{\omega}
\end{aligned}
$$

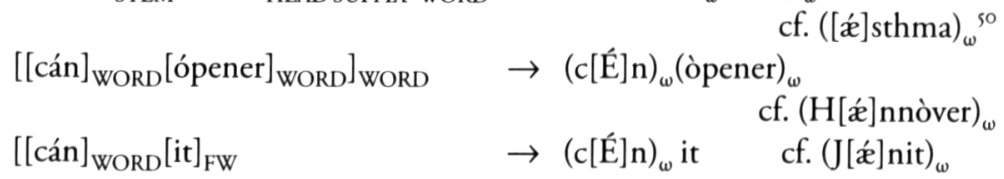

so The example is relevant only for the pronunciation with voiceless [s]. 
The phonologically unmotivated occurrence of [E] in (9I $a$ ) motivates a PU analysis:

(92)

\begin{tabular}{|c||c|c|c|}
\hline Base: $\mathrm{b}[\mathrm{E}] \mathrm{n}+\mathrm{er}$ & PU[NuC] & $x$-TENSING & ${ }^{*}$ TENSE-LOW \\
\hline \hline$(\mathrm{b}[\not ́] \text { nner })_{\omega}$ & $* !$ & & \\
\hline $\boldsymbol{\sim}\left(\mathrm{b}[\mathrm{E}]{\text { nner })_{\omega}}^{*}\right.$ & & & $*$ \\
\hline
\end{tabular}

Comparison of the prosodic structures of the complex words in (91 $a$ ) with the corresponding simplexes in the right-hand column shows that PU effects, but not boundary effects, result in contrastive distribution of the vowels (i.e. true minimal pairs).

Turning now to the predictability criterion, we find that tense $[\mathrm{E}]$ indeed occurs regularly in noncohesive contexts (cf. ((m[E]ss) $)_{\omega}$ less) $)_{\omega}$ 'massless'). By contrast, in cohesive contexts the distribution of $[æ]$ versus $[\mathrm{E}]$ is more complicated. Ferguson notes that 'the inflectional endings -es and -ing invariably preserve the identity of the stem; agentive -er generally does so, and there are occasional examples of other derivational suffixes, although most do not' (1972: 263). Some examples are given in (93).

\begin{tabular}{|c|c|c|}
\hline \multirow[t]{4}{*}{ a. No PU effect } & $(\mathrm{cl}[æ] \mathrm{ssic})_{\omega}$ & 'classic' \\
\hline & $(\operatorname{cl}[æ] \text { ssify })_{\omega}$ & 'classify' \\
\hline & $(\mathrm{m}[x] \text { ssive })_{\omega}$ & 'massive' \\
\hline & $\left(\mathrm{p}[æ]_{\text {ssage }}\right)_{\omega}$ & 'passage' \\
\hline \multirow[t]{3}{*}{ b. PU effects } & $(\mathrm{cr}[\mathrm{E}] \mathrm{sser})_{\omega}$ (cf. $\left.\mathrm{cr}[\mathrm{E}] \mathrm{ss}\right)$ & 'crasser' (comparative \\
\hline & $(\mathrm{cl}[\mathrm{E}] \mathrm{sses})_{\omega}(\mathrm{cf} . \mathrm{cl}[\mathrm{E}] \mathrm{ss})$ & 'classes' \\
\hline & $(\mathrm{m}[\mathrm{E}] \mathrm{ssing})_{\omega}$ (cf. m[E]ss) & 'massing' \\
\hline
\end{tabular}

Potential PU effects in (93a) are probably inhibited by semantic drift. While unfortunately there are no relevant test cases there is a clear prediction that tense $[\mathrm{E}]$ in noncohesive harassment would persist, even if the word developed an idiosyncratic meaning or harass became obsolete. By contrast, in cohesive suffixation like $b[\hat{E}]$ nner 'one who bans', the effect is dependent on the independent existence of the semantically closely related base form $b[\mathrm{E}] n$ 'ban', which licenses [E].

In addition to the cases in (90a), where $\mathfrak{x}$-TENSING 'over-applies', there are also several cases of 'under-application'. Ferguson (1972: 264) notes that there are 'four common verbs and two archaic forms of a common verb' which exceptionally fail to undergo æ-TENSING: am, can 'be able', ran, began, hast, hath. However, 'commonness' is not a relevant property here. Failure of $æ$-TENSING in am, can 'be able' is a domain effect, resulting from the non-alignment of pword boundaries with head function words. Additional cases of this type of 'under-application' are listed in (94a), where $æ$-TENSING never applies even under (contrastive) stress. The claim is then that there is an additional prosodic condition on $æ$-TENSING: the rule applies only if the relevant syllable is dominated by a pword. ${ }^{\text {II }}$ Failure of $\mathfrak{x}$-TENSING in ( $\left.94 a\right)$ correlates then with

st Sensitivity of the tensing rules to the pword is not an isolated phenomenon. Many cases of exceptional trimoraic internal rhymes result from an Old English rule of vowel lengthening before certain consonant 
stress instability (e.g. $\left.(æ m)_{\Sigma}-(2 \mathrm{~m})_{\sigma}\right)$, as opposed to the stable feet in $(94 b)$, which satisfy undominated HEADEDNEsS. ${ }^{52}$

$$
\begin{aligned}
& \text { a. }[\mathrm{am}]_{\mathrm{HFWORD}} \rightarrow([\dot{x}] \mathrm{m})_{\Sigma} \text { 'am' } \\
& {[\mathrm{can}]_{\text {HF WORD }} \rightarrow(\mathrm{c}[\ddot{x}] \mathrm{n})_{\Sigma} \text { 'can' }} \\
& \text { (auxiliary) } \\
& {[\text { and }]_{\text {HFWORD }} \rightarrow\left([\text { x́]nd })_{\Sigma}\right. \text { 'and' }} \\
& {[\mathrm{an}]_{\text {HF WORD }} \rightarrow\left([\text { ǽ] n })_{\Sigma}\right. \text { 'an' }} \\
& \left.[\text { than }]_{\text {HF WORD }} \rightarrow(\text { th[x́ }] \mathrm{n}\right)_{\Sigma} \text { 'than' }
\end{aligned}
$$

b. $[\mathrm{ham}]_{\mathrm{WORD}} \rightarrow(\mathrm{h}[\mathrm{E}] \mathrm{m})_{\omega}$ 'ham'

$[\mathrm{can}]_{\text {WORD }} \rightarrow(\mathrm{c}[\mathrm{E}] \mathrm{n})_{\omega}$ 'can'

$[\text { land }]_{\text {WORD }} \rightarrow(\mathrm{l}[\mathrm{E}] \mathrm{nd})_{\omega}$ ' land'

$[\mathrm{ban}]_{\mathrm{WORD}} \rightarrow(\mathrm{b}[\mathrm{E}] \mathrm{n})_{\omega}$ 'ban'

$[\mathrm{man}]_{\mathrm{WORD}} \rightarrow(\mathrm{m}[\mathrm{E}] \mathrm{n})_{\omega}$ 'man'

Turning now to Ferguson's remaining cases of under-application, failure of $\mathfrak{x}$-TENSING in ran and began is a PU effect. This is because $\mathfrak{x}$-TENSING fails precisely for derived forms based on words with some lax vowel other than $[æ]$, which are not affected by tensing. ${ }^{53}$

$$
\begin{aligned}
& \text { a. }(\mathrm{sw}[æ] \mathrm{m}) \text { 'swam'- }(\mathrm{sw}[\mathrm{I}] \mathrm{m}) \text { 'swim' } \\
& (\mathrm{r}[æ] \mathrm{n}) \text { 'ran'- }(\mathrm{r}[\Lambda] \mathrm{n}) \text { 'run' } \\
& \text { (beg[æ]n) 'began'-(beg[r]n) 'begin' }
\end{aligned}
$$
b. $\mathrm{h}[\mathrm{E}] \mathrm{m}$ 'ham' sc[E]n 'scan' $\mathrm{p}[\mathrm{E}] \mathrm{n}$ 'pan'

'Under-application' of $x$-TENSING in (95a) is described by the ranking in (96). The

\begin{tabular}{|c|c|c|c|c|}
\hline Base: $s w[\mathrm{r}] \mathrm{m}+\mathrm{PAST}$ & $\begin{array}{l}\text { Contr: } \\
\text { Tense }\end{array}$ & PU[Nuc] & $\mathfrak{x}$-TENSING & $\begin{array}{c}\text { *TENSE- } \\
\text { LOW }\end{array}$ \\
\hline$s w[E] m]_{\text {PAST }}$ & & $* *$ ! & & \\
\hline $\boldsymbol{V} s w[æ] \mathrm{m}]_{\mathrm{PAST}}$ & & * & * & \\
\hline$s w[\mathrm{r}] \mathrm{m}]_{\mathrm{PAST}}$ & *! & & & \\
\hline
\end{tabular}
candidate $s w[\mathrm{r}] \mathrm{m}]_{\mathrm{PAST}}$, which perfectly satisfies PU[Nuc] (cf. tableau (2)), is eliminated because it violates the constraint CONTR: TENSE, which requires past tense forms to differ from present tense forms (for related effects, cf. Alderete 200I; Kenstowicz, Ch. 7 above, Rebrus and Törkenczy, Ch. Io below). The candidate sw[E]m] $]_{\text {PAST }}$ which satisfies $æ$-TENSING, is eliminated because it violates PU[NUC] more than the optimal candidate $s w[æ] \mathrm{m}]_{\text {PAST }}$, which violates PU[NUC] only minimally to satisfy ConTR: TensE:

clusters (e.g. cild > ci:ld 'child', climban > cli:mban 'climb', cf. Luick (1964: 242 ff). Luick (1964: 243) notes that the rule did not apply to function words such as and, under, should, would.

$\$ 2$ The contrast in (94) thus supports the mapping of words (and modifiers), but not head function words to separate pwords. The data argue against both Selkirk's claim that 'pronounced in isolation, function words appear in strong form and are indistinguishable stress-wise and vowel quality-wise from monosyllabic lexical category items' (Selkirk 1995: 446) and McCarthy's claim that 'the normal or default condition for a function word is to be a clitic. Alignment constraints can impel a function word into PWD ['pword' R.R.] status but only under duress' (McCarthy 2002: 138). Rather, it appears that pword boundaries are always determined solely on the basis of lexical properties of input forms.

"33 Ferguson mentions the verb swam only in a footnote, perhaps, because it does not fit his characterization of the exceptions to $\boldsymbol{x}$-TENSING as 'common verbs'. Kahn's (1976) analysis of these verbs by way of extrinsically ordering ablaut is also uninsightful. 
The archaic forms of have are amenable to either the domain analysis, since they (perhaps) could be analyzed as head function words, or to the PU analysis, since their base have has a lax vowel not affected by $x$-TENSING. ${ }^{54}$

A third case of under-application also discussed by Ferguson is illustrated in (97) (cf. Kahn 1976; Benua 1995).

$\begin{array}{llll}\mathrm{P}[æ] \text { mela } & \text { 'Pamela' } & \mathrm{P}[\mathfrak{m}] \mathrm{m} & \text { 'Pam' } \\ \mathrm{J}[\mathfrak{\text { nice }} & \text { 'Janice' } & \mathrm{J}[\mathfrak{n} \text { n } & \text { 'Jan' } \\ \mathrm{M}[\mathfrak{x}] \text { ssachusetts } & \text { 'Massachusetts' } & \mathrm{M}[\mathfrak{s s} & \text { 'Mass' }\end{array}$

Benua (1995: 12) analyzes the vowel quality in the truncated forms as a violation of regular $æ$-TENSING to satisfy the higher-ranking constraint IDENT-BT [TENSE], which requires the feature [tense] in the truncated form to be identical to the corresponding feature in the base. The analysis is repeated in (98) (Tableau (20) in Benua 1995).

\begin{tabular}{|l||c|c|}
\hline Base: $[$ pæmələ] & IDENT-BT [TENSE] & æ-TENSING \\
\hline \hline a. $\boldsymbol{\sim}$ pæm & & $*$ \\
\hline b. $\quad \mathrm{pEm}$ & $* !$ & \\
\hline
\end{tabular}

While I consider the analysis basically correct I disagree with Benua's claim that the correspondence constraint refers to phonetic output forms. Instead, I suggest that $\mathrm{PU}[\mathrm{Nuc}]$ is at work again, which requires identity of nuclei in lexical representations. I assume then that the phonetic contrast between $[x]$ and $[\mathrm{E}]$ is encoded in the lexicon as a result of Lexicon Optimization (cf. Prince and Smolensky 1993), despite the largely complementary distribution. In general, I assume that all phonetic surface features are lexicalized as long as they are universally contrastive and are consistent with lexical syllable structure. The last condition is meant to account for the observation that the phonetics of pword-final consonants appears to be inaccessible to PU effects. Consider the lack of correspondence in the truncations in (99), noted by Hale, Kissock, and Reiss (1998), which is problematic for a strictly phonetic-based approach to PU.

$$
\begin{array}{ll}
\text { Pe[r]er 'Peter' } & P e\left[t^{\prime}\right] \text { e } \\
\text { Ju[r]ith 'Judith' } & J u[d] e
\end{array}
$$

It appears that the ungrammaticality of paradigmatic leveling in (99) (i.e. both $\mathrm{Pe}[\mathrm{r}] \mathrm{er}$ ${ }^{*} P e[\mathbf{r}]$ and $\left.{ }^{*} P e\left[\mathbf{t}^{\top}\right] e r-P e\left[\mathbf{t}^{\top}\right] e\right)$ is not a specific fact about English. Assuming that PU constraints apply at the lexical level and given the assumptions regarding lexical versus phonetic syllabification stated in s. 9.2.4, the possibility of leveling in (99) can perhaps be ruled out in principle. That is, whether we assume that Peter or Judith are represented with an ambisyllabic intervocalic consonant in the lexicon or not and whether we assume that ambisyllabicity is extended to the truncated form to satisfy PU or not, inviolable CONTAINMENT will result in an exclusively coda-associated pword-final

54 Recall that $\boldsymbol{x}$-TENSING applies only before voiceless fricatives. 
consonant in the phonetic representation of Pete and Jude. 55 The corresponding allophony (e.g. glottalization for $\underline{t}$ ) is an automatic consequence of the phonetic syllable structure.

(IOO)

a. lexical representation:

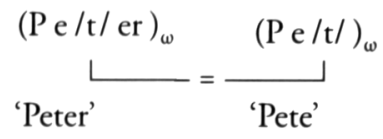

b. phonetic representation:
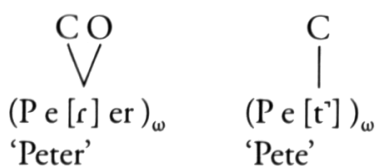

Consider next the question of why pword-final coda phonetics (as opposed to the phonetics of the nucleus) seems to be immune to undergoing paradigmatic leveling (e.g. $\operatorname{Pe}\left[\mathbf{t}^{\prime}\right] e-P e[\mathbf{r}] e r$, not ${ }^{*} P e\left[\mathbf{t}^{\prime}\right] e r$, wri $\left[\mathrm{t}^{\prime}\right] e$ 'write'-wri $[\mathbf{r}]$ er, not ${ }^{*}$ wri $\left[\mathbf{t}^{\prime}\right]$ er 'writer'). A possible explanation here is that the lexicalization of coda-specific phonetic features is blocked if the relevant consonant is associated with onset position in the lexicon. The relevant hypothesis is stated in (IOI).

(IOI) The lexicalization of syllable-conditioned phonetics presupposes nondistinct syllable structure in the lexicon.

According to (IOI) it is expected that for languages in which pword-final consonants have onset profile (e.g. English, German) the corresponding coda-conditioned phonetics cannot be lexicalized and therefore cannot give rise to PU effects. By contrast, syllable-conditioned allophonic variation affecting the nucleus is highly prone to lexicalization and, as a result, susceptible to PU constraints (cf. the data discussed in Harris 1994).

The second type of data cited by Hale, Kissock, and Reiss (1998) to refute the analysis in (98) concerns the formations in (IO2), which show 'that truncated forms may maintain vowel contrasts that are neutralized in full forms' (1998: 229).

$$
\begin{aligned}
& \mathrm{P}[ə] \text { tricia 'Patricia' } \quad \mathrm{P}[æ] \mathrm{t} \quad \text { (cf. *P[ə]t) } \\
& \text { G[ə]rard 'Gerard' } \quad \mathrm{G}[\varepsilon] \mathrm{r} \quad \text { (cf. * } \mathrm{G}[\mathrm{\partial}] \mathrm{r} \text { ) } \\
& \text { L[ə]rraine 'Lorraine' L[o]ri (cf. *L[á]ri) }
\end{aligned}
$$

55 The question of how learners know the identity of that consonant is a separate matter. If Hale, Kissock, and Reiss (1998: 229) were correct in claiming that the contrast between $/ \mathrm{t} / \mathrm{and} / \mathrm{d} / \mathrm{is}$ neutralized intervocalically then spelling would be the only source. However, there is some evidence that flapping is not a neutralizing rule. Hooper (1976) notes that flapping of $t$ blocks schwa deletion (e.g. li[rər] al 'literal' not $\left.{ }^{*} l i[\mathrm{rr}] \mathrm{al}\right)$ because of the insufficient sonority decrease between $[\mathrm{r}]$ and $[\mathrm{r}]$. By contrast, $d$ in the corresponding environment does not block schwa deletion (e.g. federal $>f e[\mathrm{dr}] \mathrm{al}$ ), which indicates that the sonority structure is different: phonetic $d$ is still a stop. Conceivably, learners need no recourse to written representation to know that Peter is represented with a $/ \mathrm{t} /$ whereas Judith is represented with a /d/ in the lexicon. 
The assertion by Hale, Kissock, and Reiss that in ( $\mathrm{IO} 2$ ) truncated forms are faithful to alleged abstract underlying forms raises the question of how those forms are learned. On the analysis proposed here phonology of truncation in (IO2) is not an identity effect of any sort but rather follows directly from undominated HEADEDNEss and is hence a domain effect. This is because truncated words, too, are mapped into pwords, which necessarily dominate a foot with the result that a full vowel (rather than a schwa) surfaces. The precise choice of the full vowel in (IO2) is apparently determined by the spelling, which means that the coinage of the truncated forms necessarily presupposes knowledge of the relevant written forms. The complete consistency of the patterns in (IO2) with those in (97) is illustrated in (IO3) ('LR' means 'lexical representation).

\begin{tabular}{|c|c|c|c|}
\hline a. LR: /pətrifə/ 'Patricia' & HEADEDNESS & PU-NuC & $\mathfrak{X}$-TENSING \\
\hline $\boldsymbol{V}(\mathrm{pæt})_{\omega}$ & & * & \\
\hline$(\mathrm{p} ә \mathrm{t})_{\omega}$ & $* !$ & wert & 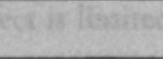 \\
\hline \multicolumn{4}{|l|}{ b. LR: /pæmələ/ 'Pamela' } \\
\hline $\boldsymbol{V}(\mathrm{pæm})_{\omega}$ & & & * \\
\hline$(\mathrm{pEm})_{\omega}$ & & $* !$ & \\
\hline
\end{tabular}

To summarize, Hale, Kissock, and Reiss (1998) fail to refute the relevance of PU constraints in truncation but merely present evidence that such constraints are violable (in contrast to Headedness and Containment) and do not apply to phonetic surface forms. Their conclusion that all truncated forms should be treated as 'lexicalized' on a par with cases like Ted (from Edward) or Bob (from Robert) misses important generalizations, including the observation that the vowel in Pam is a genuine PU effect.

\subsubsection{Alleged PU effects for l-velarization in English}

In various dialects of English the pronunciation of /1/ depends on syllable position: in exclusive onset position, so-called 'light' [1] occurs, which implies tongue-blade contact, whereas in exclusive coda position so-called dark [ł] occurs, for which tongueblade contact can be lost (i.e. a type of lenition). In addition, [ $\mathrm{t}]$ implies specific allophony of the preceding vowel illustrated in (IO4) (excerpt from the table in Hayes 2000: 93).

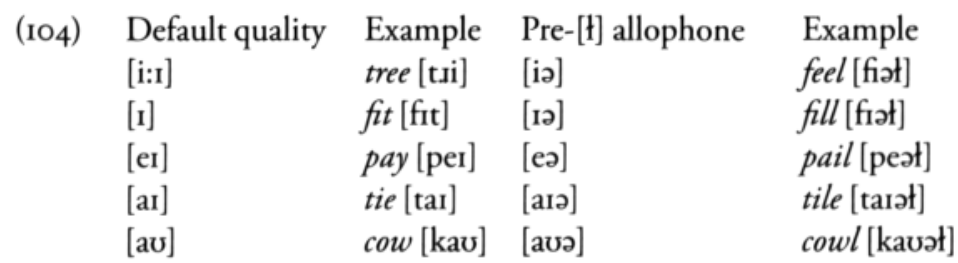


Hayes (2000) conducts an experiment where he reads a list of seventeen words both with [l] and with [t], where the two pronunciations systematically correlate with the corresponding vowel allophony illustrated in (I04). Ten informants, who were told the meanings of the words, were asked to rate the pronunciations from I designating 'just right', to 7 designating 'awful'. The results of this study for simplexes are given in (IOS), where the numbers are the mean of the judgement of all ten consultants. The characterization of syllable position is mine (based on Kahn 1976).

\begin{tabular}{|c|c|c|c|c|}
\hline \multirow{2}{*}{\multicolumn{2}{|c|}{ a. Exclusive Onset }} & light $[1]$ ight $-[1]$ ight & I. 30 & 6.10 \\
\hline & & Louánne $[1]$ ouánne- $[\mathrm{t}]$ ouánne & I.IO & 5.55 \\
\hline \multirow[t]{2}{*}{$b$. } & Exclusive Coda & bell $[\mathrm{b} \varepsilon \mathrm{l}]-[\mathrm{b} \varepsilon \partial \mathrm{t}]$ & 6.60 & 1.20 \\
\hline & & help [help]-[heəłp] & 6.60 & I.OS \\
\hline & Ambisyllabic & (Norman) Mailer [meila] - [merła $]$ & 2.00 & 2.00 \\
\hline & & Hayley (Mills) [herli] —-[heati] & I. 55 & 3.05 \\
\hline
\end{tabular}

The ratings for the two candidates in both exclusive onset and exclusive coda position are fairly clear. For the ambisyllabic context the ratings are interpreted as indicative of 'free variation' with a 'slight preference for [1]' (Hayes 2000: 95, 96)..$^{56}$

The (for the purpose of this chapter) significant part of the study concerns the ratings of $l$ in morphologically complex words. Three contexts can be distinguished in structural terms which correlate with three rating patterns:

\begin{tabular}{|c|c|c|c|c|}
\hline & Word + clitic & mail it [méılıt] - [méəłıt $]$ & 4.40 & I.IO \\
\hline & Stem + consonant- & gray-ling [gréılın]—[gréəłın] & I.39 & 3.17 \\
\hline & initial suffix & gay-ly [gérli]—[géəti] & 1.45 & 3.65 \\
\hline & & free-ly [fríli $]$ - [fríəti $]$ & 1.85 & 3.20 \\
\hline \multirow[t]{3}{*}{$c}$. & Stem + vowel-initial & mail-er [mérlə] — [méəłə] & 2.79 & 2.00 \\
\hline & suffix & hail-y [hérli]—[héəłi] & 4.00 & I. 56 \\
\hline & & $($ touchy-) feel-y [fílii $]$ - [fírti $]$ & 2.00 & 2.20 \\
\hline
\end{tabular}

In the approach to English word prosody outlined in s. 9.3 the three distinct rating patterns in (106) follow from the three distinct types of prosodic structures in (I07). That is, strong preference for dark [t] in mail it and (somewhat weaker) preference for light [ $\mathrm{l}]$ in grayling are boundary effects, which follow from the position of the laterals within the respective syllabification domains. The $l$ in mail it exhibits coda properties (i.e. it is dark) because it is syllabified as a coda to satisfy ConTaInment. Similarly, the $l$ in grayling exhibits onset properties (i.e. it is light) because it is syllabified as an onset to satisfy Containment. The stronger preference for [1] in (IO5a) compared to (IO6b) can also be explained based on prosodic context: $l$ is pword-initial in (IO5a), but not in $(106 b)$.

\footnotetext{
s6 The examples are perhaps not well-chosen as they are strongly reminiscent of suffixed words. The ratings for mellow, which is unproblematic in this regard, are not given.
} 

a. [mail $]_{\text {WORD }}[\text { it }]_{\text {HEAD FW }}$
b. $\left.[\text { gray }]_{\text {STEM }}[\text { ling }]_{\text {HEAD SUFFIX }}\right]_{\text {WORD }}$
c. $\left[[\text { mail }]_{\text {STEM }}[\mathrm{er}]_{\text {HEAD SUFFIX }}\right]_{\text {WORD }}$
$\rightarrow \quad(\text { mail })_{\omega}$ it 'mail it'
$\rightarrow \quad(\text { (gray) })_{\omega}$ ling $)_{\omega}$ 'grayling'
$\rightarrow{\text { (mailer })_{\omega}}$

Assuming the prosodic representation in (I07) the phonetics of $l$ in mailer is not a potential boundary effect. However, it is far from clear whether there is a PU effect. The ratings for dark [ $\mathrm{t}]$ in simplex Mailer and suffixed mailer are identical according to (I05c) and (I06c). It is unclear what accounts for the significant difference between the ratings for mailer, touchy-feely, which barely, if at all, deviate from simplex patterns, and haily, galy, which do deviate. Could the preferences expressed by the consultants be influenced by their desire to (artificially) express links to semantic base forms for words that are utterly obscure? Moreover, are there PU effects in cases where $l$ appears in pretonic (i.e. onset) position such as pòllée 'one who is questioned in a poll', expèllée 'one who has been expelled' and if not, why not? And if true PU effects were demonstrated in (Io6c), could it be that the relevant effect is limited to the phonetics of the vowel without affecting the pronunciation of the consonant (cf. the discussion of hypothesis (IOI) in s. 9.5.I)? Detailed experimental studies are needed to answer those questions. For now, I conclude that there are two clear boundary effects in (107a) and (107b) and an unclear PU effect in (107c), where PU possibly affects only the vowel.

Consider now Hayes's (2000) description of the data in (I06) exclusively in terms of PU. To account for the distinct ratings between mail it and mailer two separate PU constraints are introduced, PU (PhrASAL) for phrasal contexts versus PU (MoRPHOLOGICAL) for morphological contexts, 'with the former ranked within UG as necessarily stricter than the latter' (Hayes 2000: IO2). This proposal raises many questions. What exactly is the extension of the paradigm in each case? How is the attractor determined in each case? Which of the two constraints is responsible for the (presumably strongly preferred) dark [ $\mathrm{t}]$ in mail order, or is there a third constraint, PU (CoMPOUND)?

Both cases in (107b) and (I07c) are described by PU(MorpHOLOGICAL), which raises the problem that 'paradoxically, these constraints cannot be stated on /1/ per se. This is because in grayling and similar forms, the crucial light [1] does not actually occur in the base form gray' (Boersma and Hayes 200I). This paradox is solved by basing PU constraints on vowels and by specifying undominated constraints to secure the appropriate match-up of [l] and [ $\mathrm{t}]$ with the corresponding vowel allophones (cf. Hayes (2000: IOI)). The proposal is illustrated in (108), where the arrow ' $\Leftrightarrow$ ' indicates the required match-up between vowel allophones and $l$-allophone illustrated in (IO4):

$$
\text { a. } \operatorname{gr}[\underbrace{\mathrm{I}}] \Leftrightarrow[\mathrm{l}] \text { ing } \operatorname{gr}\left[\mathrm{ée}_{\mathrm{I}}\right]
$$$$
\text { b. } \mathrm{m}[\text { éə }] \Leftrightarrow[\mathrm{f}] \mathrm{er} \quad \mathrm{m}[\text { éə }] \Leftrightarrow[\mathrm{f}]
$$

The parallel treatment of the cases in (IO8) raises the question of why the preference for light $[1]$ in grayling is stronger than the preference for dark $[\mathrm{t}]$ in mailer. This contrast 
could not be caused by the pronunciation of the alleged attractors: grey is clearly pronounced with [ér] as mail is clearly pronounced with [éa]. On my view this contrast indicates that two separate phenomena are involved. Light [1] in (I08a) is a boundary effect and the alleged 'match-up' with the preceding vowel is simply a matter of 'prosodic consistency' (cf. s. 9.4.4). Internal boundary effects are excluded for mailer but a PU effect, especially one affecting the stressed nucleus, is plausible (cf. s. 9.5.I).

Additional evidence in support of the analysis of light [1] in grayling as a boundary effect comes from semantics. The sort of semantic dissociation in (I09) is unproblematic for a boundary analysis, but not for a PU analysis. Recall the data in (79), where comparable semantic dissociation inhibited any sort of paradigmatic influences from etymological base forms:

(I09) grayling 'a fresh-water fish (genus Thymallus)' versus grey 'colour term' eyelet 'a small hole through which a rope etc. is passed' versus eye 'organ of

The distribution of l-allophony in affixation based on a bound stem would be an even better testing ground. Unfortunately, there is only a single relevant example, the somewhat archaic adjective thowless defined as 'devoid of energy or spirit' in the $O E D$. There is no reason to doubt that this adjective is like reckless, hapless in that once the suffix is recognized, perhaps based on the privative meaning of the adjective or perhaps because of its spelling, its prosodic structure is indistinguishable from words based on an independently existing stem such as cowless.

$$
\begin{array}{lll}
{\left[[\text { thów }]_{\text {STEM }}[\text { less }]_{\text {HEAD SUFFIX }}\right]_{\text {WORD }}} & \left((\text { thow })_{\omega} \text { less }\right) & \text { 'thowless' } \\
{\left[[\text { ców }]_{\text {STEM }}[\text { less }]_{\text {HEAD SUFFIX }}\right]_{\text {WORD }}} & \left((\text { cow })_{\omega} \text { less }\right) & \text { 'cowless' }
\end{array}
$$

Whereas on a boundary approach the suffix-initial $l$ would be light, precisely as in cowless 'destitute of cows', ${ }^{57}$ there is a clear, but incorrect, prediction on Hayes's approach that this word must be treated like a simplex, with free variation between [ $\theta$ aulos] and [ $\theta$ auəłəs].

To summarize, Hayes's attempt to mimic the boundary effects in (106 $a, b)$ in terms of PU constraints comes not only at the expense of introducing a questionable separation of PU constraints in phrasal versus morphological constraints. In addition, the approach fails empirically in that certain boundary effects (i.e. semantically dissociated words or words based on bound stems) simply cannot be analyzed as PU effects.

\subsubsection{Alleged durational PU effects in French}

According to Rialland (1986) schwa loss in casual speech in (IIIa) does not lead to homophony with (IIIb). Rather the subtle phonetic contrasts described in (IIIc) exist.

${ }^{57} \mathrm{cf}$. the related phonetics of suffix-initial $n$ in shyness in (I). 
(III)
a. $\left[\mathrm{pad} \boldsymbol{\mathrm { s }}_{\mathrm{i}} \mathrm{Ol}\right]>\left[\mathrm{pad} \mathbf{\mathrm { s }}_{\mathrm{i}} \mathrm{Ol}\right]$
'pas de/d'rôle' 'no role'

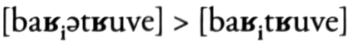
'bas re/r'trouvé' 'stocking found again'
b. [pads $\mathrm{s}_{\mathrm{j}} \mathrm{Ol}$

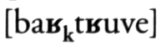
'pas drôle' 'not funny'
bar trouvé 'bar found'
c. $\mathbf{b}_{\mathbf{i}}$ exhibits typical onset properties (e.g. greater acoustic energy, longer duration, no lengthening effect on preceding vowel)
$\mathbf{G}_{\mathbf{j}}$ exhibits typical properties of a syllable internal onset (e.g. decreased energy in the higher formants, shorter duration)
$\mathbf{b}_{\mathbf{k}}$ exhibits typical coda properties (e.g. decreased energy, shorter dur- ation, lengthening effect on preceding vowel)

To account for the distribution of the b-allophones in (III) Rialland suggests that schwa loss does not imply syllable loss but results in the reassociation of the nucleus with the following consonant as in (II2b). The phonetic contrasts between (III $a$ ) and (IIIb) follow then from the distinct syllable structures in (II2b) versus (II2c).

(II2)

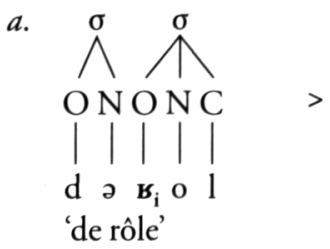

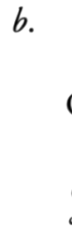

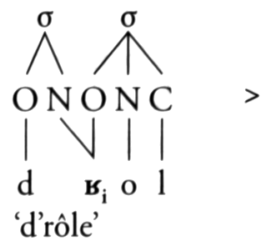

$c$.

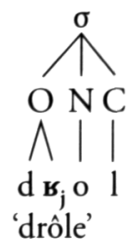

Steriade (2000) rejects Rialland's analysis because both d'rôle and drôle count as monosyllabic in metrical scansion. The association of [r] with both nucleus and onset position in (II2b), presumably a novel type of syllable structure resulting exclusively from schwa loss, seems indeed unmotivated on phonetic grounds and furthermore fails to express identity to the corresponding sound in (II2a). A serious empirical flaw concerns the fact that schwa loss in $d(e)$ rôle is treated on a par with schwa loss in the word $f(e) r a i$, which however for most speakers results in true homophony with (historically schwa-less) frais. The ' $\varnothing$ ' in (II3) marks the site of the historical schwa. ${ }^{58}$

$$
\text { a. pas } \mathrm{d}[\varnothing] \text { rôle } \neq \text { pas drôle }
$$

b. $f[\varnothing]$ rai $=$ frais

The last criticism relates to the question of acquisition. Can learners be expected to interpret the phonetic contrast perceived in pairs like drôle versus d'rôle in terms of fossilized syllable structures as in (II2)? The criticisms of Rialland's analysis are summarized in (II4).

(II4) a. incorrect predictions regarding syllable count (cf. Steriade 2000: 328);

b. questionable type of ambisyllabicity in (112b)/ introduction of novel, non-structure preserving syllable structure;

c. inadequate representation of phonetic correspondence; cf. (II2a) vs (II2b)

58 This particular difference between schwa loss in ( $113 a)$ and ( $\left.{ }^{1} 13 b\right)$ is confirmed by Caroline Féry (p.c.). Rialland (p.c.) also acknowledges that the cases in (II $3 a)$ and (II3b) differ and expresses doubt that there is any phonetic contrast in $(113 b)$. 
d. lack of discrimination between distinct types of schwa loss (cf. (II3));

$e$. the question of acquisition.

Steriade explicitly dismisses the idea of linking the allophonic distribution described in (III) to syllable structure. Instead the phonetics of $r$ in (III) is claimed to satisfy PU (Left: Duration), presupposing no contrast in syllable structure between d'rôle and drôle.

(II5) PU (Left: Duration) (Steriade 2000):

If two consonants, $\mathrm{C}$ and $\mathrm{C}^{\prime}$, stand in correspondence and $\mathrm{C}$ is morpheme initial in the careful pronunciation of the relevant morpheme, $\mathrm{C}^{\prime}$ is durationally equivalent to $\mathrm{C}$.

The analysis is illustrated in (II6), where identity expressed by ' $=$ ' is required to satisfy PU (Left: Duration), resulting in deviation from simplex phonetics expressed by ' $\neq$ '.

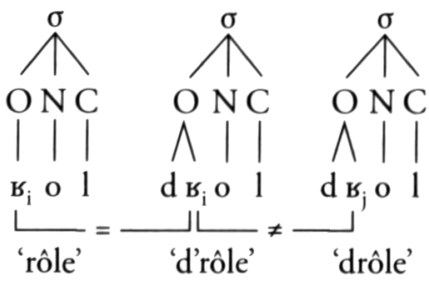

Invoking PU to account for the effect observed in (III) is questionable since nondistinct word forms belonging to a single paradigm but distinct registers are related. ${ }^{99}$ Before discussing Steriade's analysis further I will demonstrate that reference to PU constraints is unnecessary in that none of the criticisms in (II4) apply to a boundary analysis based on the syntactic distinctions specified in (II7). The crucial and, I believe, uncontroversial distinction is that $r(e)$ trouvé, but not $d(e)$ rôle, is a word. Note the use of a single phoneme $/ \mathbf{b} /$ in the left column and the predictability of the three allophones in the right column on the basis of position within the parenthesized syllabification domains (i.e. $\left[\mathrm{b}_{\mathrm{i}}\right]$ : initial, $\left[\mathrm{b}_{\mathrm{j}}\right]$ : prenuclear, non-initial, $\left[\mathrm{b}_{\mathrm{k}}\right]$ : coda).

$$
\begin{aligned}
& \text { a. }[\mathrm{pa}]_{\mathrm{MOD}}[\mathrm{d} ə]_{\mathrm{HEAD} \mathrm{FW}}[\mathrm{sol}]_{\mathrm{WORD}} \rightarrow(\mathrm{pa})(\mathrm{d} ə)\left(\mathrm{6}_{\mathrm{i}} \mathrm{ol}\right) \text { pas d'rôle } \\
& \text { 'no role' } \\
& \text { b. }[\mathrm{pa}]_{\mathrm{MOD}}[\mathrm{d}]_{\mathrm{HEAD} \mathrm{FW}}[\mathrm{rol}]_{\text {WORD }} \rightarrow(\mathrm{pad})\left(\mathbf{6}_{\mathrm{i}} \mathrm{Ol}\right) \text { pas d'rôle 'no } \\
& \text { role' } \\
& \text { c. }[\mathrm{pa}]_{\mathrm{MOD}}[\mathrm{d} \text { бol }]_{\text {WORD }} \rightarrow(\mathrm{pa})\left(\mathrm{d}_{\mathbf{r}_{\mathrm{j}}} \mathrm{ol}\right) \text { pas drôle 'not } \\
& \text { funny' } \\
& \text { d. }[\mathrm{ba}]_{\text {WORD }}\left[[\text { вә }]_{\text {MOD }}[\text { tвuve }]_{\text {WORD }}\right]_{\text {WORD }} \rightarrow \text { (ba) }\left(\mathbf{6}_{\mathbf{i}}\right. \text { ə)(tвuve) 'bas } \\
& \text { retrouvé' } \\
& \text { e. }[\mathrm{ba}]_{\text {WORD }}\left[[\mathrm{s}]_{\mathrm{MOD}}[\text { truve }]_{\text {WORD }}\right]_{\text {WORD }} \rightarrow(\mathrm{ba})\left(\mathbf{6}_{\mathrm{i}}\right. \text { truve) 'bas r'trouvé' } \\
& f \text {. [bав }]_{\text {WORD }}[\text { truve }]_{\text {WORD }} \rightarrow\left(\text { bав }_{\mathbf{k}}\right) \text { (truve) 'bar trouvé' }
\end{aligned}
$$

s9 Steriade (2000: 331) notes that her analysis agrees with Rialland's in that a characteristic property of the citation or careful form is inherited by the schwa-less variant. 
The constraints relevant for the mapping in (II7) are stated in (II8), where Nuc: Voc is the phonological markedness constraint enforcing cohesion of the consonantal morphemes in $(I 17 b, e)$. Other relevant consonants which I assume are undominated include PARSE ('every segment must be parsed into syllable structure') and SyLL: NUC ('every syllable must dominate a nucleus'), where the latter can arguably be subsumed under Headedness. Reference to pwords is avoided because in French syllabification domains fail to coincide with stress domains.

(II8) a. Nuc: Voc ('a nucleus must be filled by a vowel')

b. Align (Word, L; $\sigma, \mathrm{L}$ ), Align (Word, R; $\sigma, \mathrm{R}$ )

c. Align (Mod, L; $\sigma, \mathrm{L})$, Align (Mod, R; $\sigma, \mathrm{R}$ )

d. Align (Head FW, L; $\sigma, \mathrm{L}$ ), Align (Head FW, R; $\sigma, \mathrm{R}$ )

Nuc: Voc forces the integration of consonantal morphemes into an adjacent syllable. Ranking Align (Word, L; $\sigma, \mathrm{L}$ ) above Align (Word, R; $\sigma, \mathrm{R}$ ) causes leftward integration of the head function word in $(I I b)$ and rightward integration of the prefix in (II7e). Alternatively, one could also 'derive' the schwa-less forms by ranking the constraint *sCHWA above Nuc: Voc to describe casual speech. The first candidates listed in tableau (II9a) and (II9b), respectively, are optimal in careful speech, where *sCHWA

\begin{tabular}{|c|c|c|c|c|c|}
\hline a. & {$[\mathrm{pa}]_{\mathrm{MOD}}[\mathrm{d} ə]_{\mathrm{FUNCWORD}}[\mathrm{rol}]_{\text {WORD }}$} & $\underset{*}{\mathbb{Z}}$ & 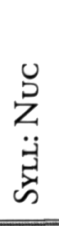 & 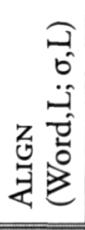 & 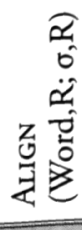 \\
\hline & $(\mathrm{pa})_{\sigma}(\mathrm{d} \partial)_{\sigma}(\text { воl })_{\sigma}$ & $* !$ & & & \\
\hline & $(\mathrm{pa})_{\sigma}(\mathrm{d})_{\sigma}(\text { сооl })_{\sigma}$ & & *! & 60 & \\
\hline & $(\mathrm{pa})_{\sigma}(\mathrm{d} \text { воl })_{\sigma}$ & & & $* !$ & \\
\hline \multicolumn{6}{|c|}{$\sqrt{ }(\mathrm{pad})_{\sigma}(\text { воl })_{\sigma}$} \\
\hline \multirow[t]{4}{*}{$b}$. & {$[\mathrm{ba}]_{\text {WORD }}\left[[\mathrm{b} \partial]_{\text {MOD }}[\text { truve }]_{\text {WORD }}\right]_{\text {WORD }}$} & & & & \\
\hline & $(\mathrm{ba})_{\sigma}(\text { вә })_{\sigma}(\text { truve })_{\sigma}$ & $* !$ & $4 n+1$ & 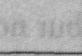 & \\
\hline & $(\mathrm{ba})_{\sigma}(\text { в })_{\sigma}(\text { truve })_{\sigma}$ & & $* !$ & & \\
\hline & $(\text { (аав })_{\sigma}(\text { tъuve })_{\sigma}$ & & & $*$ & $* !$ \\
\hline$\sqrt{ }$ & $(\mathrm{ba})_{\sigma}(\text { (ьtьuve })_{\sigma}$ & & & $*$ & \\
\hline & {$\left[\right.$ fəธع $_{\text {WORD }}$} & & & & \\
\hline & $(\text { fәธع })_{\sigma}$ & $* !$ & & & \\
\hline$\sqrt{ }$ & $\left(f_{\mathbf{L} \varepsilon}\right)_{\sigma}$ & & & & \\
\hline
\end{tabular}


ranks lower than the constraints in (I18). For both registers the alignment constraints in $(\mathrm{II} 8 c, d)$ rank below the constraint in (II8a).

The description in (II9) agrees with Rialland's analysis (and differs from Steriade's $\mathrm{PU}$ analysis) in that the subphonemic contrasts are interpreted in terms of distinct syllable structures as shown in (120) but none of the criticisms in (114) apply. Both pas drôle and pas d'rôle are bisyllabic (cf.(II4a)), the description is entirely 'structure-preserving' as no new type of syllable structure is introduced (cf. (II 4 b)) and phonetic correspondence is related to corresponding syllable structures (cf. (II4c)). The phonetic contrast between schwa loss in $d(e)$ rôle compared to $f(e)$ rais is explained (cf. (II $d d)$ ). Finally, the description causes no problems for acquisition, assuming that children recognize the difference between words and function words (cf. (II 4 )).
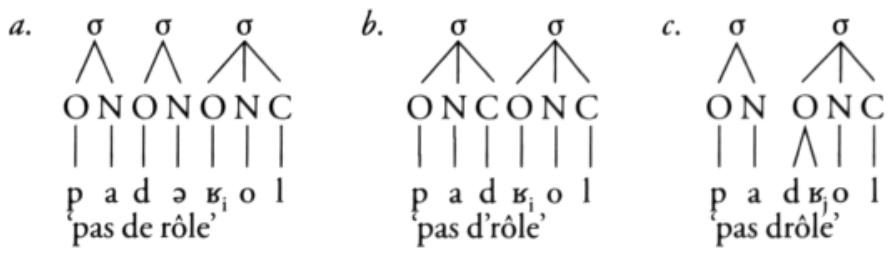

Unlike Rialland's analysis, the domain analysis relates the distribution of $\underline{\underline{r}}$-allophones in (III) to subphonemic syllabification effects which do not involve distinct registers. Consider now the boldfaced contrasts for (121 $\left.a, a^{\prime}\right),\left(\mathrm{I} 2 \mathrm{I} b, b^{\prime}\right)$ and (121 $\left.c, c^{\prime}\right)$ respectively, which are determined by contrasts in morphosyntactic structure.

$$
\begin{aligned}
& \text { a. [reste } \left.]_{\text {WORD }} \rightarrow \text { (к[вs.t] }\right) \text { rester 'remain' } \\
& a^{\prime} .\left[[\mathrm{de}]_{\mathrm{MOD}}[\text { stabilize }]_{\text {WORD }}\right]_{\text {WORD }} \rightarrow(\mathrm{d}[\mathrm{e}])_{\sigma}(\text { stabilize })_{\sigma} \text { déstabilizer } \\
& \text { b. [syblime }]_{\text {WORD }} \rightarrow \text { (sy[.bl]ime) sublimer 'sublimate' } \\
& b^{\prime} .\left[[\text { syb }]_{\text {MOD }}[\text { légyal }]_{\text {WORD }}\right]_{\text {WORD }} \rightarrow(\text { sy }[\mathbf{b}])_{\sigma}(\text { légyal })_{\sigma} \quad \text { 'sublingual' } \\
& \text { c. [diatonik }]_{\text {WORD }} \rightarrow\left(\mathrm{d}[\mathrm{j}] \text { atonik) }{ }_{\sigma}\right. \text { 'diatonique' 'diatonic' } \\
& c^{\prime} .\left[[\mathrm{di}]_{\text {MOD }}[\text { atomik }]_{\text {WORD }}\right]_{\text {WORD }} \rightarrow(\mathrm{d}[\mathrm{i}])_{\sigma}(\text { atomik })_{\sigma} \text { 'diatomique' }
\end{aligned}
$$

'diatomic'

Word-internally, the cluster st is heterosyllabic in French. As a result, lax $[\varepsilon]$ as in (121a), but not tense [e], may precede st because of a rule known as 'Closed Syllable Adjustment' (cf. Schane 1968; Lowenstamm 198I). A (noncoronal) stop is syllabified as onset before [1] as in (12Ib). Finally, to satisfy the constraint ${ }^{*}[\mathrm{~V} . \mathrm{V}]$, which prohibits hiatus, [i] loses its syllabicity before [a] as in (I2Ic) (cf. Gougenheim 1935; Johnson 1987). The specific types of violations of these regular syllable patterns boldfaced in ( $\left.121 a^{\prime}, b^{\prime}, c^{\prime}\right)$ follow immediately from the satisfaction of the alignment constraints in (I18). The (erroneous) impression that in French the phrase, rather than the word, constitutes the domain for syllabification is presumably due to undominated ONSET, which induces cohesion for all consonant-final morphemes followed by 
vowel-initial morphemes thereby causing prosodic neutralization as in (122). ${ }^{60}$
a. [inisjal $]_{\text {WORD }}$
$\rightarrow \quad([i . n i]$ sjal) initial 'initial'
b. $\left[[\text { in }]_{\text {MOD }}[\text { imitabl }]_{\text {WORD }}\right]_{\text {WORD }}$
$\rightarrow \quad([i . n i]$ mitabl) inimitable 'inimitable’

Unlike ONSET, the second phonological constraint triggering cohesion, the above mentioned constraint ${ }^{*}[\mathrm{~V} . \mathrm{V}]$, does not dominate all alignment constraints. Rather, cohesion results across stem boundaries as in (I22a), but not across word boundaries as in $(122 b)$.

$$
\begin{array}{ll}
{\left[[\mathrm{kJl} b \mathrm{i} i]_{\text {STEM }}[\mathrm{al}]_{\text {HEAD SUFFIX }}\right]_{\text {WORD }}} & \rightarrow(\mathrm{k} \text { lon }[\mathrm{j}] \mathrm{al})_{\sigma} \text { 'colonial' } \\
{\left[[\text { səmi }]_{\text {MOD }}[\mathrm{abid}]_{\text {WORD }}\right]_{\text {WORD }} \rightarrow(\operatorname{səm}[\mathrm{i}])_{\sigma}(\text { arid })_{\sigma} \text { 'semi-arid' }}
\end{array}
$$

Returning to Steriade's analysis it appears that the constraint PU: LefT Duration mimics certain aspects of ALIGN (Word, L; $\sigma, \mathrm{L}$ ) and associated Containment effects. Given that the problem with Rialland's analysis concerning syllable count, as well as the remaining problems in (II4), can be solved within a domain analysis in which a single representation of $/ \mathrm{s} /$ is assumed in the lexicon (cf. (II9)) it is unnecessary to assume the lexical representation of various (universally) nondistinctive allophones implied by the PU analysis. The French data therefore do not refute the notion of (universal) distinctiveness as an essential property of lexical phonological structure.

Given the immense theoretical significance of the question of whether the PU analysis of subphonemic contrast in cases like (III) is valid it is perhaps important to go beyond demonstrating that reference to PU constraints is superfluous and to present evidence for empirical inadequacy. The PU analysis fails to account for prosodic consistency in that only domain-initial, but not the corresponding domain-final, boundary effects are expressed. Steriade mentions some relevant data in her informal discussion: 'It is the relative duration of $a$ in [ba] and the syllable-initial properties of [в] in [вәтьиче] that are preserved in the corresponding schwa-less phrase [bавtьuve].' While the relevant data could conceivably be described by positing additional PU constraints to describe 'morpheme-final' phonetics, the systematic clustering of the relevant effects would not be captured (cf. the Prosodic Consistency Criterion in (8I)). The Casual Speech Criterion in (84), if valid, would also rule out a PU analysis as for instance casual [pad. воl] 'pas d'rôle' exhibits a sound property (i.e. a heterosyllabic cluster [d. в]), which occurs neither in corresponding careful pronunciation (i.e. [pa. dəьоl] nor in the casual pronunciation of simplexes.

Coda syllabification of morpheme-initial $d$ in [pad. sol] 'pas d'rôle', which violates PU: (Left: Duration), brings to light the major challenge for a PU based analysis, that is, to account for cohesion. Why do function words consisting of a single consonant fail PU if the following word starts with a consonant? (Because PU: Nuc forces

\footnotetext{
${ }^{60}$ Pulgram (1970: 86) characterizes French as a language "in which words lose both their segmental and their suprasegmental identity within the cursus'. However, the examples cited in support of this claim involve cohesion to satisfy ONSET. Regular boundary effects are observed in other contexts (cf. the distinct syllabification of trois petites roues versus trois petits trous discussed by D. Jones (1931: 60)).
} 
leftward cohesion.) Why is Steriade's constraint PU: (Left: Duration) in (II5) limited to consonants? (Because high-ranking ONSET causes cohesion for many vowelinitial morphemes.) Why is there a PU effect for final [i] in prefixes, but not in stems? (Because Align (Word, L; $\sigma, \mathrm{L}$ ) dominates *[V.V], causing cohesion of suffixes.) None of the relevant phenomena can be explained in terms of a $\mathrm{PU}$ analysis but they strongly motivate a boundary approach. ${ }^{61}$

\subsection{CONCLUSIONS}

In this chapter I have argued for the necessity of properly distinguishing PU effects from domain effects and have proposed various criteria for doing so. Proper distinction of the relevant phenomena is a crucial prerequisite for all further inquiry. PU effects, once they have been properly delimited, shed light on many aspects of lexical structure of major concern to linguists, including the organization of paradigms in the mental lexicon and the question of which phonetic features are represented in the lexicon. Mostly false conclusions will be drawn on the basis of misclassified PU effects.

${ }^{61}$ Unlike the French data, Steriade's second example, the occurrence of a flap in capi[r]alistic, but not in mili[t]aristic, observed by Withgott (1982), is not a boundary effect (both words are single pwords:

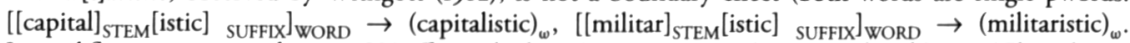
Instead flapping in capitalistic is a PU effect, which, as Pater (2000: 270) suggested and Davis (Ch. 5 above) shows in detail, affects not low-level phonetics but (lexical) foot structure. 